Supporting Information for:

\title{
Aqueous $\mathrm{TiO}_{2}$ Nanoparticles React by Proton-Coupled Electron Transfer
}

Jennifer L. Peper, Noreen E. Gentry, Benjamin Boudy, and James M. Mayer*

Department of Chemistry, Yale University, New Haven, Connecticut 06520-8107, United States james.mayer@yale.edu

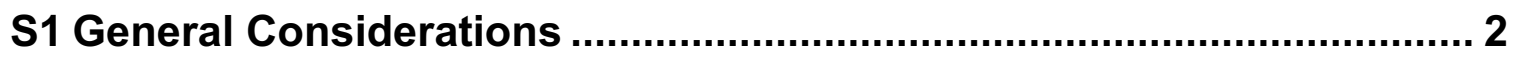

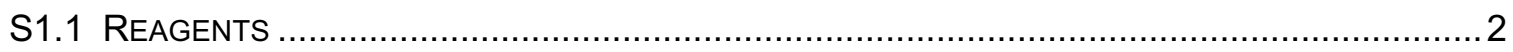

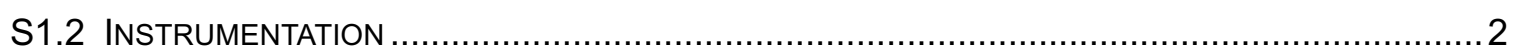

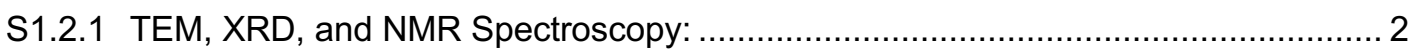

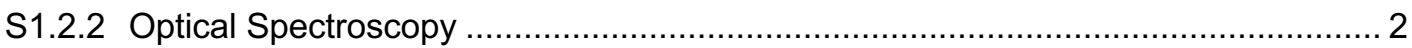

S1.2.3 Phase Analysis Light Scattering (PALS) and Dynamic Light Scattering (DLS) ........ 2

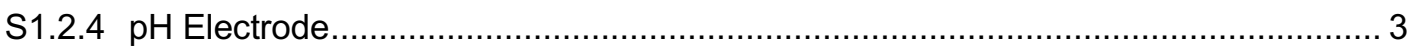

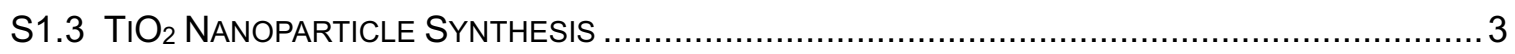

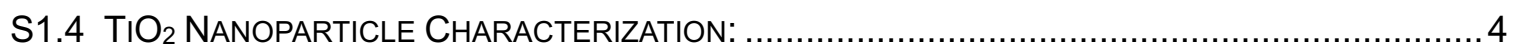

S1.5 DETERMINING NANOPARTICLE CONCENTRATION IN COLLOIDS: ......................................... 5

S1.6 StABILITY OF UNCAPPED AND CITRATE CAPPED TIO 2 NANOPARTICLES: ............................. 7

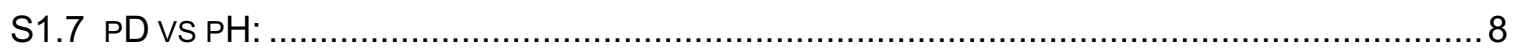

S2 Photochemical Reduction of $\mathrm{TiO}_{2}$ Nanoparticles ................................ 9

S2.1 NP SAMPLE PREPARATION FOR PHOtOCHEMICAL REDUCTION ....................................... 9

S2.2 QUANTIFICATION OF AdDITIONAL E IN TIO ${ }^{R}$ COLLOIDS ........................................... 11

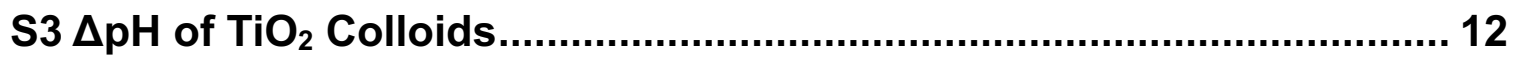

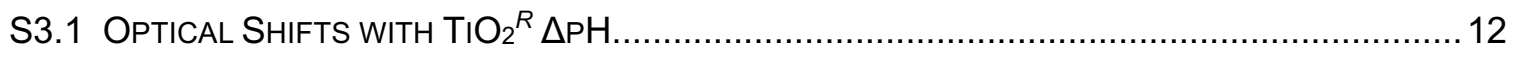

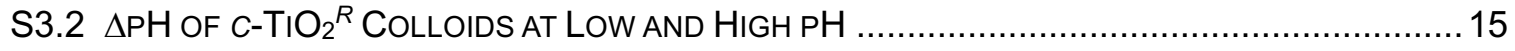

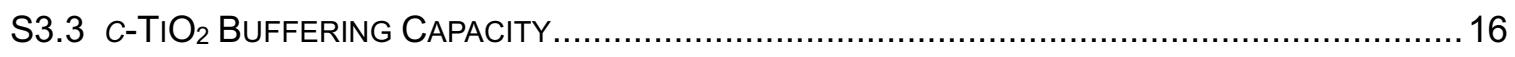

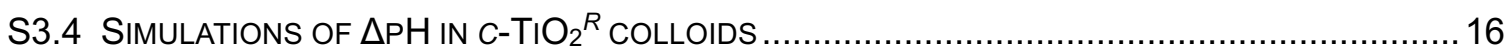

S3.4.1 $\Delta \mathrm{pH}$ Simulations for $\mathrm{c}-\mathrm{TiO}_{2}$ Photochemical Reduction ...................................... 17

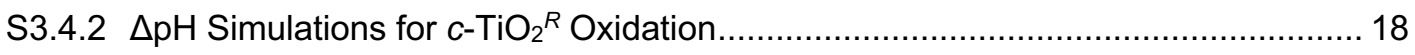

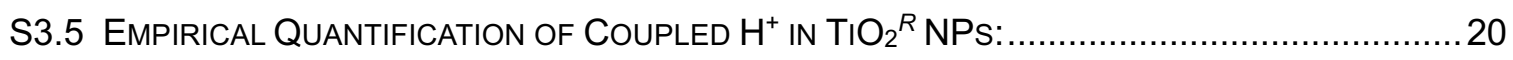

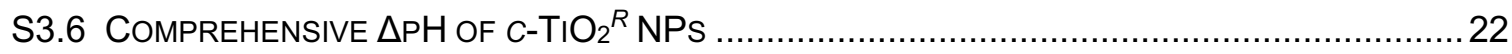

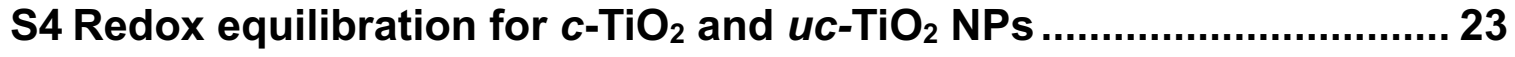

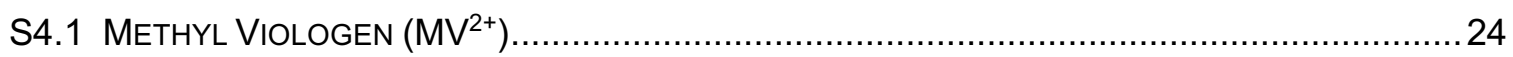

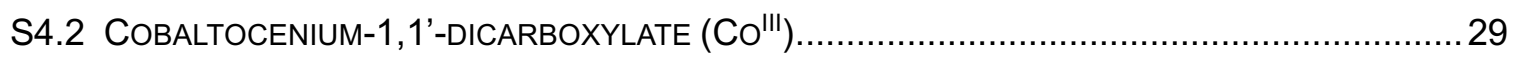

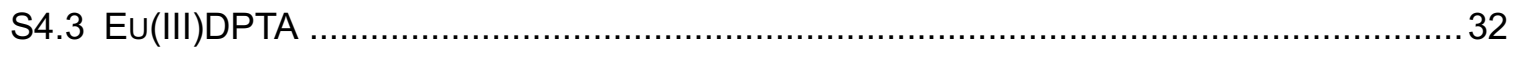

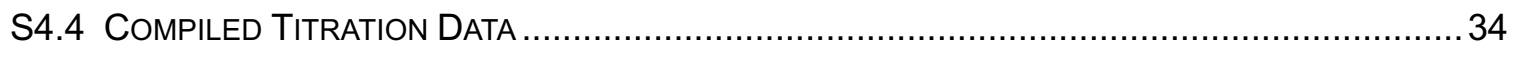

S5 References for Supporting Information.............................................. 36 


\section{S1 General Considerations}

For ease of access for the reader, Sections S1.1-1.5 in this document contain large portions of text and figures copied from the Supporting Information sections of our previous papers that used the same titanium dioxide nanoparticles. ${ }^{1,2}$

\section{S1.1 Reagents}

All reagents were used as received apart from titanium tetrachloride $\left(\mathrm{TiCl}_{4}\right)$ and 4-methoxy-2,2,6,6tetramethyl-1-piperidinyloxy (4-MeO-TEMPO), which were purified as follows. $\mathrm{TiCl}_{4}$ was distilled immediately before use in the synthesis of $\mathrm{TiO}_{2}$ nanoparticles (NPs), and 4-MeO-TEMPO was sublimed and stored at $4{ }^{\circ} \mathrm{C}$.

$18 \mathrm{M} \Omega \cdot \mathrm{cm}$ water $\left(\mathrm{H}_{2} \mathrm{O}\right)$ from a Synergy ${ }^{\circledR}$ Milli-Q system was used in all cases during synthesis and for resuspension of $\mathrm{TiO}_{2} \mathrm{NPs}$, except for experiments utilizing ${ }^{1} \mathrm{H}-\mathrm{NMR}$ spectroscopy, for which deuterated solvents $\left(\mathrm{D}_{2} \mathrm{O}\right.$ and methanol-d $\left.\mathrm{d}_{4}\right)$ were used for $\mathrm{TiO}_{2} \mathrm{NP}$ resuspension.

$\mathrm{TiCl}_{4}, 4-\mathrm{MeO}-\mathrm{TEMPO}$, potassium iodide $(\mathrm{KI})$, iodine $\left(\mathrm{I}_{2}\right)$, methyl viologen dichloride hydrate $\left(\mathrm{MV}^{2+}\right)$, and $\mathrm{D}_{2} \mathrm{O}$ were purchased from Sigma-Aldrich. Europium(III) oxide was purchased from Allied Chemical. Methanol $(\mathrm{MeOH})$, citric acid monohydrate, and $\mathrm{HCl}$ were purchased from Fisher Chemical, and methanol$\mathrm{d}_{4}$ was acquired from Cambridge Isotope Laboratories.

\section{S1.2 Instrumentation}

\section{S1.2.1 TEM, XRD, and NMR Spectroscopy:}

Transmission electron microscopy (TEM) images of the $\mathrm{TiO}_{2} \mathrm{NPs}$ were collected with a FEI Tecnai Osiris $200 \mathrm{kV}$ transmission electron microscope.

Room temperature X-ray diffraction (XRD) data of solid $\mathrm{TiO}_{2} \mathrm{NPs}$ were collected with a Rigaku MiniFlex ( $\mathrm{Cu} \mathrm{K \alpha} ; \lambda=1.54178 \AA$ ) coupled to a scintillation counter detector. Line profiles of the 2D diffraction data were integrated and processed with the Rigaku 2DP software package.

${ }^{1} \mathrm{H}$ NMR spectra were collected using a Bruker AV500 spectrometer. Ethanol was added as an internal standard.

\section{S1.2.2 Optical Spectroscopy}

All optical spectra were collected using either a Hewlett Packard (Agilent) 8453, a Cary 60, or a Cary 5000 spectrometer.

\section{S1.2.3 Phase Analysis Light Scattering (PALS) and Dynamic Light Scattering (DLS)}

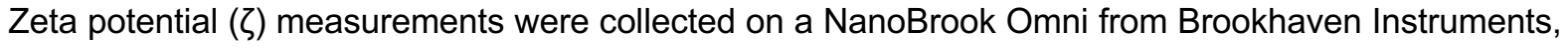
using Phase Analysis Light Scattering (PALS). A laser wavelength of $640 \mathrm{~nm}$ was used, and 10 measurements were averaged per sample. 
Dynamic light scattering (DLS) measurements were conducted at a fixed angle of $155^{\circ}$ using an ALV5000 (ALV GmbH) and a $532 \mathrm{~nm}$ laser (Coherent, Verdi V2). For each sample 10 DLS measurements were obtained with a collection time of $30 \mathrm{~s}$ each. On-board correlator cards provided the scattered light intensity correlation functions $G(\mathrm{~T})$, which were fit to a second-order exponential decay function to obtain average diffusive time scales via a cumulant analysis. Particle sizes, including hydrodynamic radii, were obtained using an assumption of spherical particles and the Stokes Einstein relation. CONTIN analysis of the raw data was used to obtain particle size distributions. ${ }^{3,4}$

\section{S1.2.4 pH Electrode}

All $\mathrm{pH}$ measurements were collected using a Thermo Scientific ${ }^{\mathrm{TM}}$ Orion $^{\mathrm{TM}}$ PerpHecT $^{\mathrm{TM}}$ ROSS $^{\mathrm{TM}}$ Combination pH Micro Electrode, calibrated using five NIST pH standard solutions in water $\left(\mathrm{H}_{2} \mathrm{O}\right)$ from BrandNu: $1.68,4.01,7.00,10.01,12.68$. Corrections for samples in $\mathrm{D}_{2} \mathrm{O}$ were made after the measurement, as detailed in Section S1.7.

\section{S1.3 $\mathrm{TiO}_{2}$ Nanoparticle Synthesis}

Uncapped NPs: Uncapped $\mathrm{TiO}_{2}$ nanoparticles $\left(u c-\mathrm{TiO}_{2}\right)$ were synthesized via the hydrolysis of $\mathrm{TiCl}_{4}$ as previously described by Mohamed et al. ${ }^{5}$ with few revisions. Freshly distilled titanium tetrachloride $\left(\mathrm{TiCl}_{4}\right.$, $\left.2 \mathrm{~mL}, 27.4 \mathrm{mmol},-20^{\circ} \mathrm{C}\right)$ was added drop-wise to $18 \mathrm{M} \Omega \cdot \mathrm{cm}$ water $\left(600 \mathrm{~mL}, 0{ }^{\circ} \mathrm{C}\right)$ with vigorous stirring. Caution: $\mathrm{TiCl}_{4}$ reacts vigorously with water/water vapor to form $\mathrm{HCl}$ vapor. The distillation and all transfers of $\mathrm{TiCl}_{4}$ should be handled with care. After 1 hour, the resulting acidic reaction mixture was dialyzed against $18 \cdot \mathrm{M} \Omega \cdot \mathrm{cm}$ water until a $\mathrm{pH}$ of $2.0-2.3$ was achieved $(2-4 \mathrm{~h})$. The resulting colloidal suspension is stable at $4{ }^{\circ} \mathrm{C}$ for several days. Removal of solvent in vacuo $\left(20 \mathrm{mbar}, 25^{\circ} \mathrm{C}\right.$ ) yielded a shiny white solid (uc- $\mathrm{TiO}_{2}$ solid product). Strict adherence to the specified temperature and vacuum strength for solvent removal were crucial for successful resuspension of the nanoparticles. The $u c-\mathrm{TiO}_{2}$ solid product was stable for several months and was re-suspended immediately before use in neutral $18 \mathrm{M} \Omega \cdot \mathrm{cm}$ water $\left(3 \mathrm{~g} u c-\mathrm{TiO}_{2}\right.$ solid product $\mathrm{L}^{-1}$ ) to give a transparent solution with $\mathrm{pH}$ 2.0-2.3. It is important to note that the concentration of $u c-\mathrm{TiO}_{2}$ in the resuspended colloid is less than $3 \mathrm{~g} / \mathrm{L}$ due to residual $\mathrm{H}_{2} \mathrm{O}, \mathrm{HCl}$, and $\mathrm{Cl}^{-}$in the $u c-\mathrm{TiO}_{2}$ solid product, see Section S1.5 for details. In ${ }^{1} \mathrm{H}$ NMR experiments, deuterated solvents were used.

Citrate Capped NPs: Citrate capped $\mathrm{TiO}_{2}$ nanoparticles $\left(c-\mathrm{TiO}_{2}\right)$ were prepared using $u c-\mathrm{TiO}_{2}$ solid product, which was resuspended in neutral $18 \mathrm{M} \Omega \cdot \mathrm{cm}$ water at $3 \mathrm{~g} / \mathrm{L}$. The addition of citric acid monohydrate (4-20 mM) resulted in a cloudy white solution and a decrease in $\mathrm{pH}$. Concentrated aqueous tetramethylammonium hydroxide $\left(\mathrm{NMe}_{4} \mathrm{OH}\right)$ was added dropwise into the rapidly stirring solution and the solution returned to clear and colorless. The resuspension of individual nanoparticles was confirmed by dynamic light scattering (DLS). 


\section{S1.4 $\mathrm{TiO}_{2}$ Nanoparticle Characterization:}

Uncapped NPs: The uc- $-\mathrm{TiO}_{2}$ NPs were imaged by transmission electron microscopy (TEM) using the FEI Tecnai Osiris $200 \mathrm{kV}$ microscope. $u c-\mathrm{TiO}_{2}$ solid product was suspended in $18 \mathrm{M} \Omega \cdot \mathrm{cm}$ water at a concentration of $0.03 \mathrm{~g} \mathrm{~L}^{-1}$, and $5 \mu \mathrm{L}$ was deposited onto a copper TEM grid (ultrathin carbon film on lacey carbon support). Two example TEM images $(A)$ and a histogram of NP diameter $(d)(B)$ are shown in Figure S1 below. A Gaussian fit of the sized NPs gives $d=4 \pm 1 \mathrm{~nm}$.
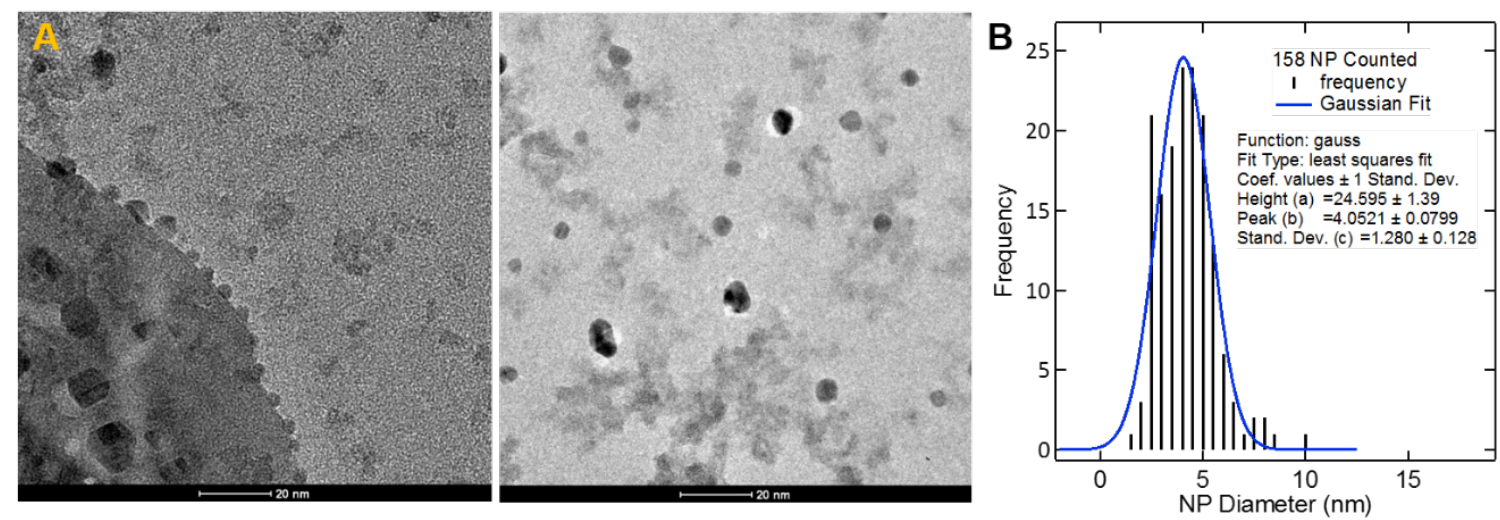

Figure S1: (A) TEM images of $u c-\mathrm{TiO}_{2}$ NPs. The scale bar is equal to $20 \mathrm{~nm}$. (B) Histogram of NP diameter vs frequency and the corresponding Gaussian fit (blue trace) for 158 counted nanoparticles. Reproduced from Peper, J. L.; Vinyard, D. J.; Brudvig, G. W.; Mayer, J. M., J. Am. Chem. Soc. 2017, 139, 2868. Copyright 2017 American Chemical Society.

Before analysis of the solid $u c-\mathrm{TiO}_{2}$ product by X-ray diffraction (XRD), the solid product was ground with a mortar and pestle into a fine powder and placed onto a glass slide. A powder XRD pattern of the solid $\mathrm{TiO}_{2}$ product was then collected (at room temperature) with a Rigaku MiniFlex 600 (Cu Ka; $\lambda=1.54178$ A) coupled to a scintillation counter detector.

The diffraction pattern of $\mathrm{TiO}_{2} \mathrm{NPs}$ is plotted in Figure $\mathrm{S} 2$ alongside the expected peaks of anatase (COD ID 1010942) and rutile (COD ID 9001681). Powder patterns were calculated from the aforementioned, published crystallographic diffraction patterns using the software Mercury. Although the diffraction peaks of small NPs are expected to be broad, peak positions of the $\mathrm{TiO}_{2}$ diffraction pattern are consistent with the peaks of the anatase lattice. The full width at half $\max (\mathrm{FWHM})$ at 2 theta $=25.2$ and 53.8 give a diameter, $d=3.5 \pm 0.1 \mathrm{~nm}$, by the Scherrer equation. This is consistent with the TEM results reported above. 


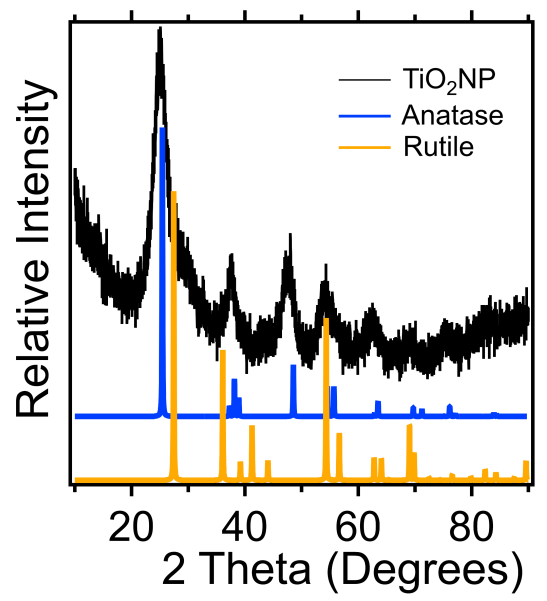

Figure S2: The $u c-\mathrm{TiO}_{2}$ diffraction pattern (black) is plotted against the calculated diffraction patterns of anatase (blue, COD ID 1010942) and rutile (yellow, COD ID 9001681). Reproduced from the Supporting Information of Peper, J. L.; Gentry, N. E.; Brezny, A. C.; Field, M. J.; Green, M. T.; Mayer, J. M. J. Phys. Chem. C 2021, 125, 680. Copyright 2021 American Chemical Society.

Citrate Capped NPs: The $c-\mathrm{TiO}_{2}$ NPs were imaged by TEM using the same instrument and method as the $u c-\mathrm{TiO}_{2}$. Figure $\mathrm{S} 3$ below shows an example TEM image (A) and a histogram of NP diameter as determined from 28 measured NPs. The Gaussian fit estimates a diameter of roughly $d=4.2 \pm 1 \mathrm{~nm}$, only slightly larger than $u c-\mathrm{TiO}_{2}$ but well within the same range for these amorphous colloids.
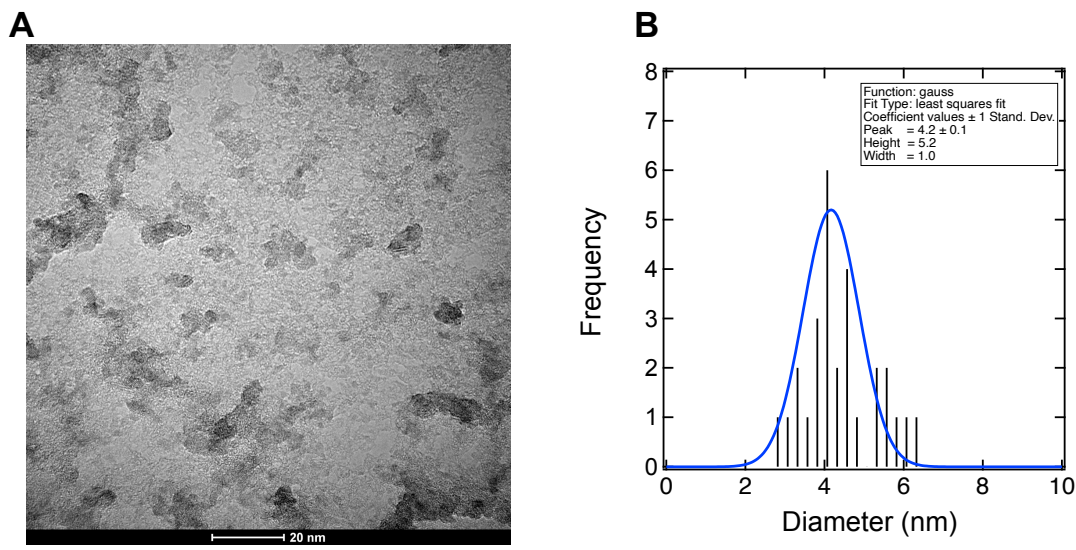

Figure S3: (A) A representative TEM image of $c-\mathrm{TiO}_{2}$. The scalebar is equal to $20 \mathrm{~nm}$. (B) Histogram of NP diameter (nm) vs. the frequency of NPs in that range. A Gaussian fit is shown in blue of 28 counted nanoparticles, giving an average size of $4.2 \pm 1 \mathrm{~nm}$

\section{S1.5 Determining Nanoparticle Concentration in Colloids:}

After calcination at $450^{\circ} \mathrm{C}$ for $6 \mathrm{~h}$, the mass of $u c-\mathrm{TiO}_{2}$ solid samples decreased by $25 \%$. This decrease is attributed to the presence of residual water and $\mathrm{HCl}$ from the synthesis in the solid $\mathrm{TiO}_{2}$ product. Thus, our use of the phrase "solid $\mathrm{TiO}_{2}$ product" is to indicate our synthesized product rather than pure isolated $\mathrm{TiO}_{2}$. Based on the acidic $\mathrm{pH}$ of the resuspended colloid (as prepare colloids are $\mathrm{pH} 2.2$ ), the $u c-\mathrm{TiO}_{2}$ solid 
product is at least $7 \%$ by weight $\mathrm{HCl}$ with residual water accounting for the remaining mass loss. $u c-\mathrm{TiO}_{2}$ samples that are calcined or exposed to strong vacuum do not resuspend in water to form a transparent, stable colloid. Therefore, the residual water and acid likely play an important role in stabilizing the nanoparticles upon resuspension.

From these results, the resuspended colloids $\left(3 \mathrm{~g} u c-\mathrm{TiO}_{2}\right.$ solid product $\left.\mathrm{L}^{-1}\right)$ were determined to be 28 $\pm 3 \mathrm{mM}$ in $u c-\mathrm{TiO}_{2}$ (eq S1.1). Based on the known density of the anatase $u c-\mathrm{TiO}_{2}$ lattice $\left(3.894 \mathrm{~g} \mathrm{~cm}^{-3}\right)$ and the measured NP radius $(r)$, the mass of a single $u c-\mathrm{TiO}_{2}$ nanoparticle and the concentration of NPs in the

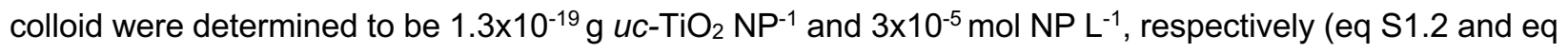
S1.3). ${ }^{5}$ For reference, $u c-\mathrm{TiO}_{2}$ nanoparticles of this size have ca. $1000 \mathrm{Ti}$ atoms per NP.

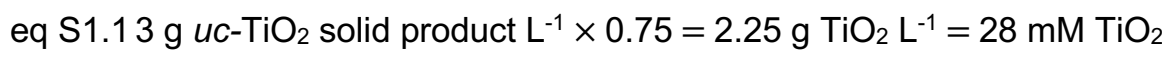

eq $51.2(4 / 3) \pi r^{3} \times 6.894 \mathrm{~g} / \mathrm{cm}^{3}=1.3 \times 10^{-19} \mathrm{~g} / \mathrm{NP}=$ NP Mass

eq $\mathrm{S} 1.31 .7 \times 10^{19} \mathrm{NP} \mathrm{L}^{-1} \div 6.022 \times 10^{23} \mathrm{NPs} / \mathrm{mol} \mathrm{NP}=2.8 \times 10^{-5} \mathrm{~mol} \mathrm{NP} \mathrm{L}^{-1}$ 


\section{S1.6 Stability of Uncapped and Citrate capped $\mathrm{TiO}_{2}$ Nanoparticles:}

Uncapped NPs: Studies of the $u c-\mathrm{TiO}_{2}$ were limited to high and low $\mathrm{pH}$ ranges $(2.8>\mathrm{pH}>9.5)$ where the acid-base functionality of the oxide surface serves as an electrostatic stabilizing barrier. ${ }^{6}$ The high surface charges of $u c-\mathrm{TiO}_{2} \mathrm{NPs}$ at extreme pHs are reflected in the large Zeta potentials $(\zeta)$ of these colloids, ca. $+40 \mathrm{mV}$ at low $\mathrm{pH}$ and ca. $-50 \mathrm{mV}$ at high $\mathrm{pH}$ (Figure S4B). Measured by phase analysis light scattering (PALS), $\zeta$ is the electrical potential at the hydrodynamic slipping plane surrounding the nanoparticle surface, resulting from the net charge of the amphoteric nanoparticle surface and the closely associated ions and solvent molecules, Figure S4A. ${ }^{7}$ As a representation of surface charge, extreme positive or negative $\zeta$ values indicate stable colloidal suspensions. At or near the point of zero charge of $\mathrm{TiO}_{2}$, when the nanoparticle net surface charge is closer to neutral $\left(\mathrm{pH}_{\mathrm{pzc}}=3.5-7.5\right), u c-\mathrm{TiO}_{2}$ colloids agglomerate..$^{6-9}$

A

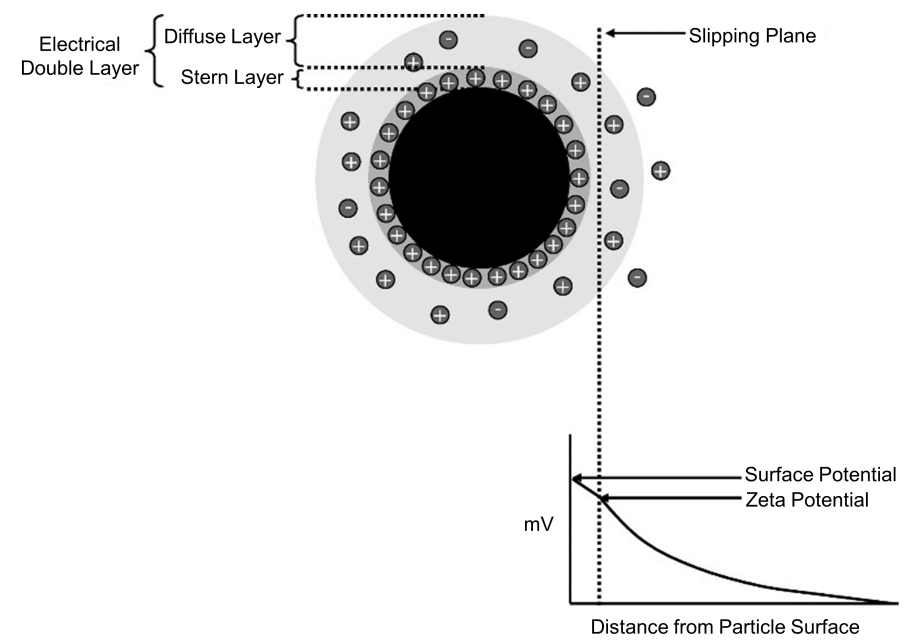

B

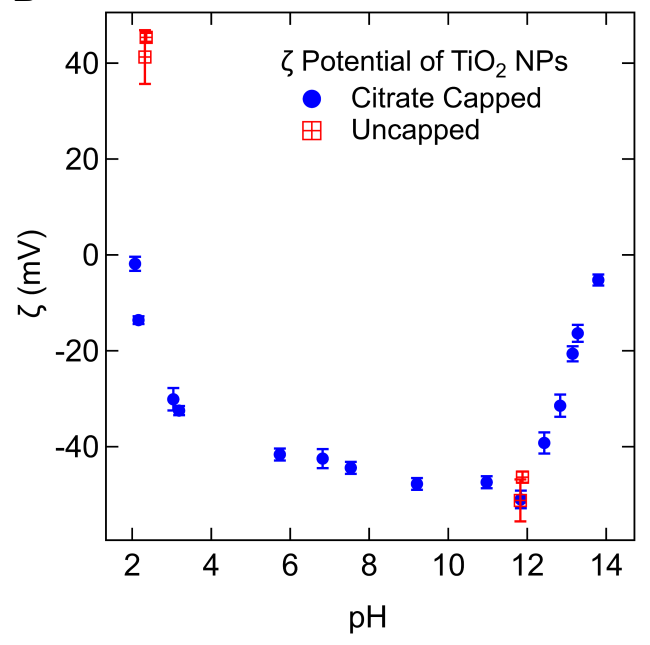

Figure S4: (A) A negatively charged NP (black sphere) in aqueous solution surrounded by strongly bound (stern layer) and loosely associated (diffusion layer) ions. The movement of the charged NP in response to an electric field (electrophoresis) results in the concurrent movement of ions within a certain boundary known as the slipping plane. $\zeta$ is the electrical potential at the slipping plane and reflects the NP surface charge. Reprinted from Kaszuba, M.; Corbett, J.; Watson, F. M.; Jones, A., High-Concentration Zeta Potential Measurements Using Light-Scattering Techniques. Philos. Trans. Royal Soc. A 2010, 368, 44394451, https://royalsocietypublishing.org/doi/full/10.1098/rsta.2010.0175. (B) The $\zeta$ potential of an as prepared, uncapped $(30 \pm 5 \mu \mathrm{M} \mathrm{NP})$ and citrate capped (blue circle) $c-\mathrm{TiO}_{2} \mathrm{NP}$ colloids (6 mM citric acid, $30 \pm 5 \mu \mathrm{M} \mathrm{NP}$ ) as a function of $\mathrm{pH}$. The citrate capped colloid was titrated with tetramethylammonium hydroxide $\left(\mathrm{NMe}{ }_{4} \mathrm{OH}\right.$, aq, $\left.\mathrm{pH} 13.4,0.25 \mathrm{M}\right)$, and the $\mathrm{pH}$ of the uncapped colloid was altered with $\mathrm{HCl}$ and $\mathrm{NMe}_{4} \mathrm{OH}$.

Basification of the $u c-\mathrm{TiO}_{2}$ was achieved via slow dropwise addition of the as prepared ( $\mathrm{pH} 2.3$ ) colloid to a vigorously stirred aqueous solution of concentrated tetramethylammonium hydroxide $\left(\mathrm{NMe}_{4} \mathrm{OH}\right)$. The volume of aq $\mathrm{NMe}_{4} \mathrm{OH}$ was predetermined to ensure a final $\mathrm{pH}>9.5$. Subsequent re-acidification of the

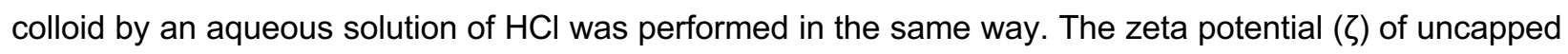


$\mathrm{TiO}_{2} \mathrm{NP}$ oscillates between $+50 \mathrm{mV}$ and $-50 \mathrm{mV}$ with subsequent changes in $\mathrm{pH}$ (Figure S5). With this method stable $u c-\mathrm{TiO}_{2}$ colloids at $\mathrm{pH}<2.5$ and $\mathrm{pH}>9.5$ were prepared.

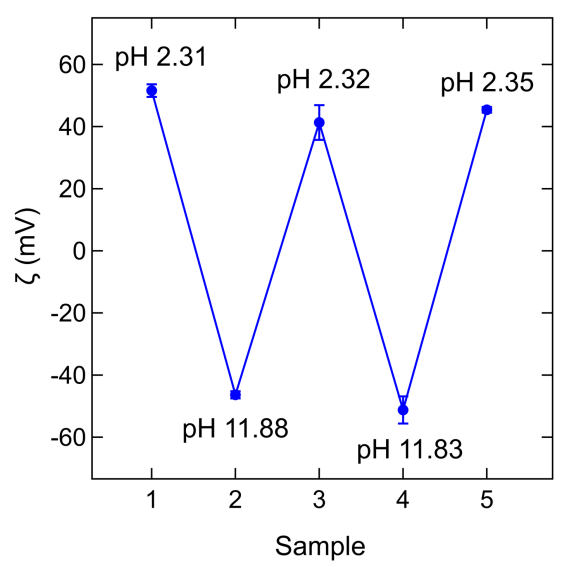

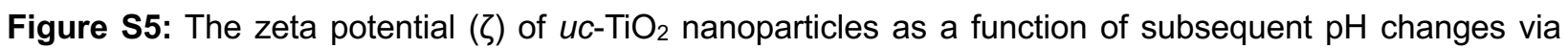
addition of aqueous $\mathrm{NMe}_{4} \mathrm{OH}(80 \mathrm{mM})$ or $\mathrm{HCl}(84 \mathrm{mM})$, showing good reversibility under these conditions (see, however Figure S8C). Prior to $\zeta$ measurement, the colloid was diluted 10 -fold with either $\mathrm{pH} 2.1 \mathrm{or} \mathrm{pH}$ $11.9 \mathrm{H}_{2} \mathrm{O}$.

Citrate Capped NPs: PALS measurements of $c-\mathrm{TiO}_{2}$ revealed negative zeta potentials $(\zeta)$ above $\mathrm{pH} 3$ (Figure S4B). Since the $u c-\mathrm{TiO}_{2}$ surface is positive or near neutral at $\mathrm{pH} 3$ (the $\mathrm{pH}_{\mathrm{pzc}}=3.5-7.5$ ), ${ }^{6-9}$ the negative zeta potential measured in these experiments indicates that citrate ${ }^{n-}$, where $n$ - is -1 to -3 , is closely associated with the nanoparticle surface. According to one study, the $p K_{a}$ values of the triprotic acid decrease to below 2 upon binding to $\mathrm{TiO}_{2}$ through the carboxylic acid functionality, i.e. bound citrate is fully deprotonated with a 3-charge at $\mathrm{pH}>3.5$. ${ }^{10}$ We did not explore the nature of $\mathrm{TiO}_{2}$ bound citric acid in this study. However, it is clear that the stability of $\mathrm{TiO}_{2}$ over this wide $\mathrm{pH}$ range results from the electrostatic net negative charge of the nanoparticle surface and citrate ligands.

\section{S1.7 pD vs pH:}

To determine the acidity and basicity of solutions, the solution $\mathrm{pH}$ was measured using a $\mathrm{H}_{2} \mathrm{O}$-calibrated $\mathrm{pH}$ electrode. Measurements of $\mathrm{D}_{2} \mathrm{O}$-based solutions using a standard $\mathrm{H}_{2} \mathrm{O}$ glass $\mathrm{pH}$ electrode are denoted $\mathrm{pH}^{*}$. Because the dissociation constant of $\mathrm{H}_{2} \mathrm{O}$ is different from $\mathrm{D}_{2} \mathrm{O}\left(\mathrm{pK}_{\mathrm{w}}{ }^{\mathrm{H}}=14.00, \mathrm{pK}_{\mathrm{w}} \mathrm{D}=14.95\right), \mathrm{pH}^{*}$ must be adjusted in heavy water solutions. The adjusted value, named $\mathrm{pD}$, is comparable to the $\mathrm{pH}$ of analogous $\mathrm{H}_{2} \mathrm{O}$ solutions. In this study, we followed the various literature reports that added 0.40-0.45 to $\mathrm{pH}^{*}$ to obtain $\mathrm{pD} .{ }^{11-14}$ Subtle differences in $\mathrm{pD}$ from these corrections are relatively small in the large scale of the $\mathrm{pH}$ ranges studied here. 


\section{S2 Photochemical Reduction of $\mathrm{TiO}_{2}$ Nanoparticles}

NP reduction was achieved via an anaerobic UV-photochemical process, similar to previous descriptions. ${ }^{1,2,5,10,15-17}$ A $100 \mathrm{~W}$ Oriel $\mathrm{Hg}$ lamp was used as the light source, and all NP photolyses took place in nitrogen-filled, quartz vessels. The lamp was set so the focal point of the light ran through the middle of the $\mathrm{TiO}_{2}$ solutions. All samples were stirred rapidly during the photolysis to achieve even reduction. Because the lifetime of the photo-generated exciton is very short, ca $25 \mathrm{~ns},{ }^{18}$ the binding affinity of the sacrificial reductant to the NP surface has a large impact on the rate of $\mathrm{TiO}_{2}$ photochemical reduction. The association of methanol and water to the $\mathrm{TiO}_{2}$ surface are relatively similar resulting in much slower photo-reduction rates. ${ }^{19}$ In contrast, the high binding affinity of citric acid to the oxide surface results in fast photochemical reduction of $\mathrm{TiO}_{2}$, even at relatively low concentrations (4-20 mM citric acid vs. $100 \mathrm{mM}$ $\mathrm{MeOH}$ ). Similar levels of reduction for $u c-\mathrm{TiO}_{2}$ and $c-\mathrm{TiO}_{2}$ occurred on very different timescales, $4-5$ hours vs. 1-5 minutes, respectively.

\section{S2.1 NP Sample Preparation for Photochemical Reduction}

Uncapped NPs: Solid $u c-\mathrm{TiO}_{2}$ was resuspended in water $\left(3 \mathrm{~g} u c-\mathrm{TiO}_{2}\right.$ solid product $\left.\mathrm{L}^{-1}\right)$ and methanol was added as a sacrificial reductant $(100 \mathrm{mM})$. Samples were degassed under nitrogen and photolysis of $u c-\mathrm{TiO}_{2}(\mathrm{pH} 2.3,100 \mathrm{mM} \mathrm{MeOH}$ ) for 4-6 hours typically resulted in the addition of $\sim 1 \mathrm{mM}$ electrons to the colloid, which corresponds to 20-50 additional $e^{-} / \mathrm{NP}\left(\sim 10^{21} \mathrm{e}^{-} \mathrm{cm}^{-3}\right)$ (Section S2.2). ${ }^{5,15}$ To aid with heat dissipation and temperature regulation, samples that were photolyzed longer than $\sim 10$ minutes were placed in a small water bath with a quartz window and the $\mathrm{TiO}_{2}$ vessel was placed very near to the quartz window to minimize the light's pathlength through the water bath. A fish pump was used to flow the water in the small bath through a larger reservoir.

Citrate Capped NPs: $\mathrm{C}-\mathrm{TiO}_{2}$ was prepared as described in Section S1.3. Citric acid monohydrate (4$20 \mathrm{mM}$ ) served as the both the capping ligand and sacrificial reductant and samples were photolyzed at $\sim \mathrm{pH}$ 4-5.5. Full $\mathrm{pH}$ equilibration of $c-\mathrm{TiO}_{2}$ lasted on range of hours, so reduced colloids were allowed to fully equilibrate before $c-\mathrm{TiO}_{2}{ }^{R}$ was used in any studies. Photolysis of $c-\mathrm{TiO}_{2}(\mathrm{pH} 4-5.5,4-20 \mathrm{mM}$ citric acid) for 1-5 minutes typically gave ca. $1 \mathrm{mM}$ additional electrons. The faster rate of this photochemical process is consistent with the higher surface binding affinity of citrate ${ }^{n-}$ relative to $\mathrm{MeOH}$.

To our knowledge citric acid has not been previously used specifically as a sacrificial reductant for metal oxides. However, the photo driven aerobic oxidations of citric acid and other organic molecules at $\mathrm{TiO}_{2}$ solid-solution interfaces have been extensively studied. ${ }^{16}$ Apart from the involvement of $\mathrm{O}_{2}$ derived reactive radical species $\left({ }^{\circ} \mathrm{OH},{ }^{\cdot} \mathrm{O}_{2}{ }^{-}\right.$, and ${ }^{\circ} \mathrm{HO}_{2}$ ), the mechanisms of citric acid oxidation at $\mathrm{TiO}_{2}$ under the anaerobic conditions studied here are likely similar to those reported for the analogous aerobic processes. ${ }^{16,20}$

Beginning with the photo-generation of an exciton at $\mathrm{TiO}_{2},\left(e^{-} \mathrm{CB}, h^{+} \mathrm{VB}\right)$, the valence band hole $\left(h^{+} \mathrm{VB}\right)$ is quenched via proton-coupled oxidation of citric acid (step 1, Scheme S1). In the absence of oxygen, the $\mathrm{TiO}_{2}$-based conduction band electron ( $\left.e^{-} \mathrm{CB}\right)$ persists, and the highly reducing alkyl radical losses a second hydrogen atom equivalent (step 2, Scheme S1). In addition to several oxidation products (acetoacetic, lactic, pyruvic, malic, glycolic, acetic, and formic acid and acetone), 3-oxoglutaric acid (3-OGA) was 
previously identified as the most common product in the aerobic photochemical oxidation of citric acid at $\mathrm{TiO}_{2}{ }^{16,20}$ In the non-redox decarboxylation of 3-OGA, two additional equivalents of $\mathrm{CO}_{2}$ and acetone may be generated (step 3, Scheme S1). Under the aqueous conditions studied here, carbonic acid is formed from the reaction of $\mathrm{CO}_{2}$ and $\mathrm{H}_{2} \mathrm{O}$. Similar to the proton-coupled oxidation of methanol to formaldehyde at $\mathrm{TiO}_{2},{ }^{15}$ Scheme $\mathrm{S} 1$ shows the generation of net two electron and two protons per photo-oxidized citric acid.

Scheme S1: Proposed mechanisms ${ }^{16,20}$ for the photochemical oxidation of citric acid at $c$ - $\mathrm{TiO}_{2}$ under anaerobic conditions.

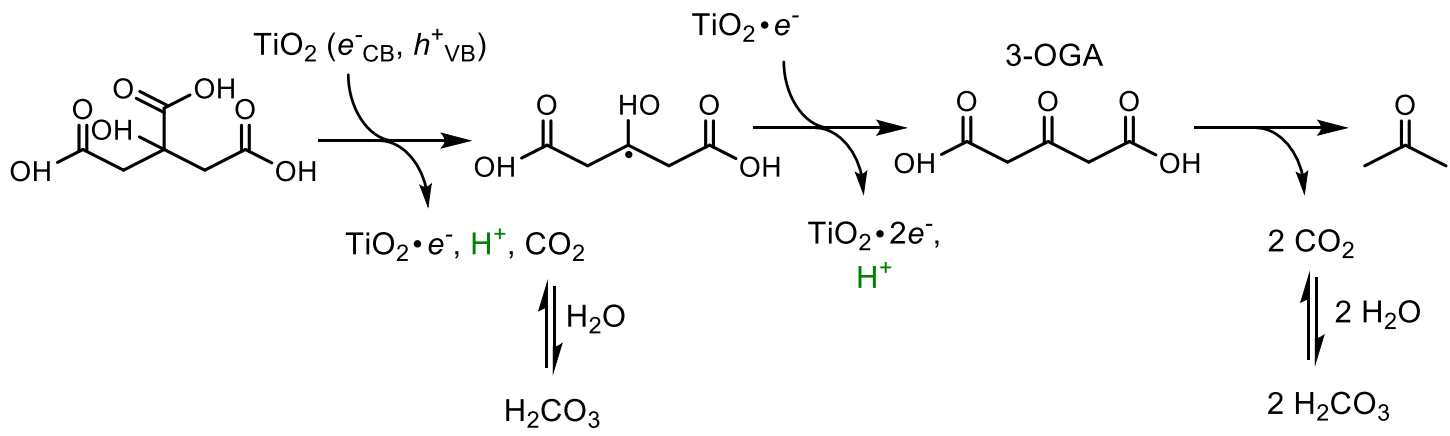




\section{S2.2 Quantification of Additional $e^{-}$in $\mathrm{TiO}_{2}{ }^{R}$ Colloids}

The additional electrons in reduced colloids $\left(u c-\mathrm{TiO}_{2}{ }^{R}\right.$ and $\left.c-\mathrm{TiO}_{2}{ }^{R}\right)$ were quantified via spectrophotochemical titrations. Titrations were performed in a nitrogen-filled glove box using a Cary 5000 and fiber optics. Various oxidants were used titrated into $\mathrm{TiO}_{2}{ }^{R}$ including potassium triiodide, $\mathrm{KI}_{3}$ (Figure S6), 4-MeO-TEMPO (Figure S7), cobaltocenium-1,1'-dicarboxylate $\left(\mathrm{Co}^{3+}\left(\mathrm{Cp}-\mathrm{COO}^{-}\right)_{2}, \mathrm{pH}>9\right)$ and methyl viologen $\left(\mathrm{MV}^{2+}, \mathrm{pH}>9\right)$.

eq S2.1 $\mathrm{A}_{600 \mathrm{~nm}} \times \operatorname{Vol} \mathrm{ltot}(\mathrm{L})=\mathrm{mol} \mathrm{e}^{-} \times \varepsilon\left(\mathrm{M}^{-1} \mathrm{~cm}^{-1}\right) \times l(\mathrm{~cm})$

A

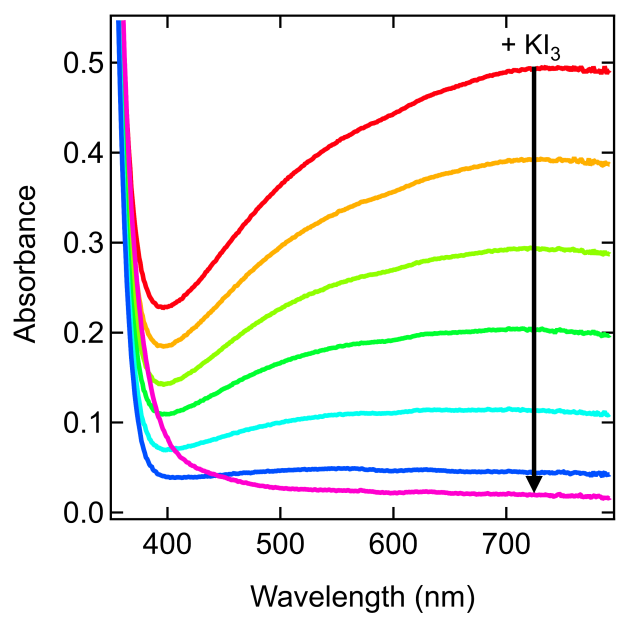

B

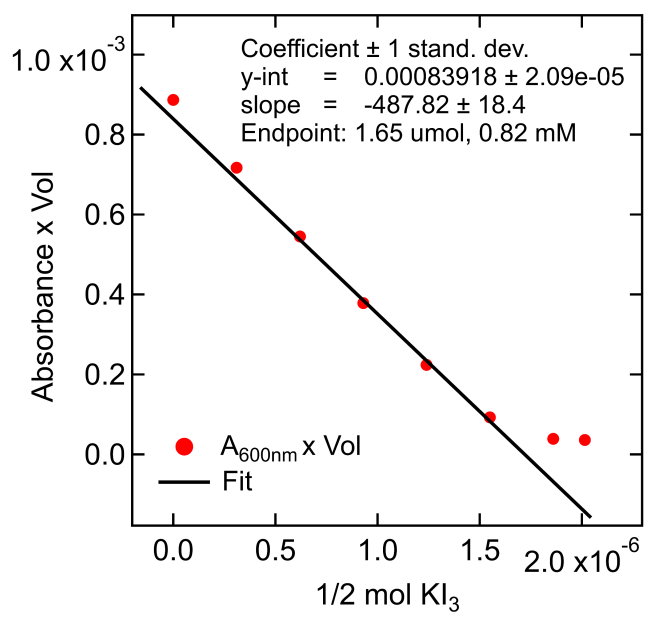

Figure S6: (A) The disappearance of the broad $c-\mathrm{TiO}_{2}{ }^{R}(\mathrm{pH} 9.1, \sim 30 \mu \mathrm{M}$ NP, $5.6 \mathrm{mM}$ citric acid) optical signal upon addition of potassium triiodide $\left(8 \mathrm{mM} \mathrm{KI}_{3}\right)$. (B) The product of $c-\mathrm{TiO}_{2}{ }^{R}$ absorbance at $600 \mathrm{~nm}$ and the total cuvette volume plotted versus $1 / 2$ moles of added $\mathrm{KI}_{3}$. The slope of the black line is the negative value of the molar extinction coefficient. The electron concentration $\left(\mathrm{mol} e^{-} \mathrm{L}^{-1}\right)$ in $c-\mathrm{TiO}_{2}{ }^{R}$ (eq S2.1) is determined using the intersection of the negatively sloped line with the final baseline points.

The addition of $\mathrm{Kl}_{3}$ aliquots to $c-\mathrm{TiO}_{2}{ }^{R}$ led to the systematic disappearance of the broad $\mathrm{TiO}_{2}{ }^{R}$ absorbance as a function of added $\mathrm{Kl}_{3}$ is shown in Figure $\mathrm{S} 6 \mathrm{~A}$. The total quantity of additional electrons in the $c-\mathrm{TiO}_{2}{ }^{R}$ was determined from the endpoint of the titration (Figure S6B). Beer's Law plots (eq S2.1, where $l$ is path length) gave the molar extinction coefficient $(\varepsilon)$ describing the electron concentration in the colloid (mol $e^{-} \mathrm{L}^{-1}$ ) as (Figure S6B). In order to account for the dilution that occurs during the titrations, the traditional form of Beer's law was multiplied by total volume (Voltot) in eq S2.1, and mol are used in place of molar concentrations.

The analogous Beer's law plot following the titration of $u c-\mathrm{TiO}_{2}{ }^{R}(\mathrm{pH} 2.1,30 \mu \mathrm{M} \mathrm{NP})$ by 4-MeO-TEMPO, a well-established hydrogen atom acceptor, is shown in Figure S7A. The appearance of new diamagnetic signals in the ${ }^{1} \mathrm{H}$ NMR spectrum is consistent with the formation of 4-MeO-TEMPOH $\left(\mathrm{H}^{+}\right)(\mathrm{N}$-protonated 4MeO-TEMPOH; Figure S7B. An unknown TEMPO derived species, accounting for less than $3 \mathrm{~mol} \%$ is marked by the black crosses. 
A

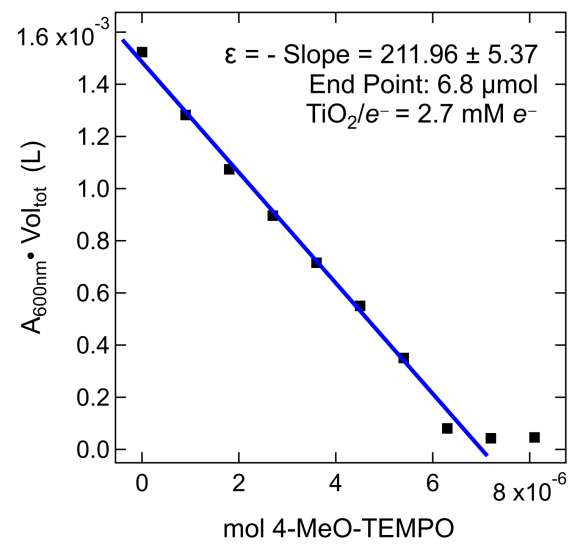

B

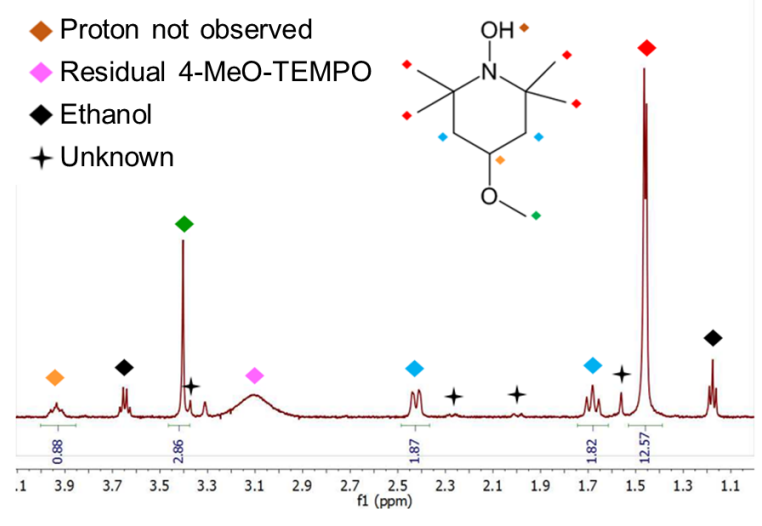

Figure S7: (A) The product of $u c-\mathrm{TiO}_{2}{ }^{R}$ absorbance at $600 \mathrm{~nm}$ and the total cuvette volume is plotted versus moles of added 4-MeO-TEMPO from the titration of $u c-\mathrm{TiO}_{2}{ }^{R}(\mathrm{pH} 2.1,30 \mu \mathrm{M} \mathrm{NP})$ by 4-MeO-TEMPO. The slope of the blue line is the negative value of the molar extinction coefficient describing the electron concentration ( $\mathrm{mol} \mathrm{e} \mathrm{e}^{-} \mathrm{L}^{-1}$ ) in $\mathrm{TiO}_{2}{ }^{R}$ (eq S2.1). (B) The ${ }^{1} \mathrm{H}$ NMR spectrum of the reaction between uncapped $\mathrm{TiO}_{2}{ }^{R} \mathrm{NP}(\mathrm{pD} 2.0$ ) and 4-MeO-TEMPO. The peak colors are coordinated to the 4-MeO-TEMPOH structure, ethanol (used as an internal standard), and an unknown species (ca. 3 mol\%). Reproduced from the Supporting Information of Peper, J. L.; Vinyard, D. J.; Brudvig, G. W.; Mayer, J. M., J. Am. Chem. Soc. 2017, 139, 2868. Copyright 2017 American Chemical Society.

\section{S3 $\Delta \mathrm{pH}$ of $\mathrm{TiO}_{2}$ Colloids}

\section{S3.1 Optical Shifts with $\mathrm{TiO}_{2}{ }^{R} \Delta \mathrm{pH}$}

Changes in the $\mathrm{pH}$ of $u c-\mathrm{TiO}_{2}{ }^{R}$ and $c-\mathrm{TiO}_{2}{ }^{R}$ resulted in large and reversible changes in the optical spectrum of the colloids. Generally, the broad $\mathrm{TiO}_{2}{ }^{R}$ absorbance increased and redshifted upon basification of the colloids. This result is seen clearly in the Beer's law plots presented above in Figure S6B and Figure S7A where the epsilon of $c-\mathrm{TiO}_{2}{ }^{R}$ at $\mathrm{pH} \sim 9\left(488 \mathrm{M}^{-1} \mathrm{~cm}^{-1}\right)$ is roughly 2.3 times larger than the epsilon of $u c-$ $\mathrm{TiO}_{2}{ }^{R}$ at $\mathrm{pH} \sim 2\left(212 \mathrm{M}^{-1} \mathrm{~cm}^{-1}\right)$.

Uncapped NPs: $u c-\mathrm{TiO}_{2}{ }^{R} \mathrm{NPs}$ agglomerate at near neutral $\mathrm{pH}$, when close to the $\mathrm{pH}_{\mathrm{pzc}}$ of $\mathrm{TiO}_{2}$. However, changes in the colloid $\mathrm{pH}$, with minimum precipitation, were achieved via rapid shifts between the stable high $\left(>\mathrm{pH}\right.$ 9.5) and low $(<\mathrm{pH} 2.5) \mathrm{pH}$ regimes using either $\mathrm{NMe}_{4} \mathrm{OH}$ or $\mathrm{HCl}$. These changes were achieved via the slow, dropwise addition of acidic $u c-\mathrm{TiO}_{2}$ into a rapidly stirring base solution, or basic $u c-\mathrm{TiO}_{2}$ into acid. Shown in Figure S8A are the spectra of $u c-\mathrm{TiO}_{2}{ }^{R}$ before and after successive pH changes. The basification of a $u c-\mathrm{TiO}_{2}{ }^{R}$ colloid from $\mathrm{pH} 2.14$ to 11.89 resulted in an immediate increase in the solution coloration and a redshift in the broad optical feature to form a new, defined peak at $790 \mathrm{~nm}$. By eye, the original, pale blue solution color was restored when the solution $\mathrm{pH}$ was decreased $(\mathrm{pH}$ 2.13). Compared to the original acidic colloid, the optical spectrum of the re-acidified sample displays increased absorbance near the $\mathrm{TiO}_{2}$ band edge and decreased absorbance at longer wavelengths. Further basification of the colloid to $\mathrm{pH} 11.97$ resulted in a spectrum matching the original basic sample. In general, the considerable change in $\mathrm{TiO}_{2}{ }^{R}$ absorbance with $\mathrm{pH}$ is reversible, as shown in Figure S8B. 
A

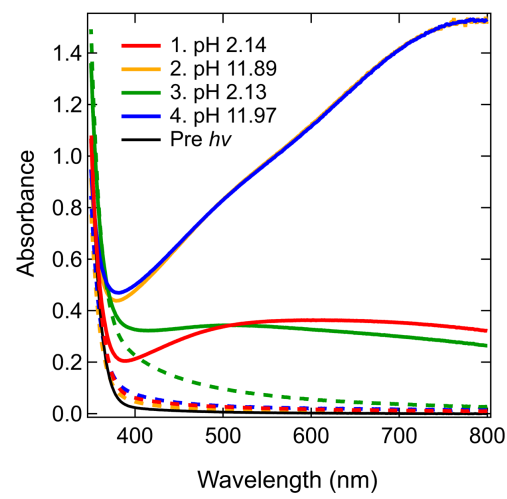

B

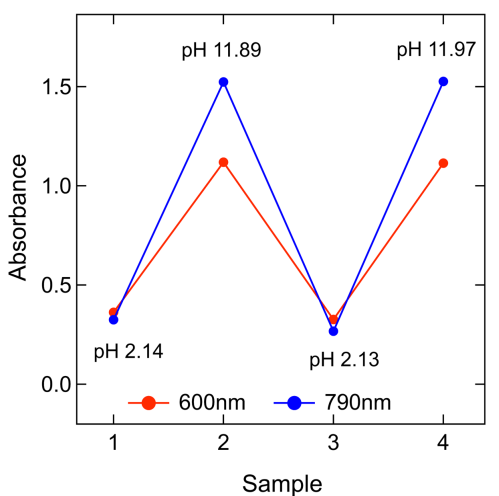

C

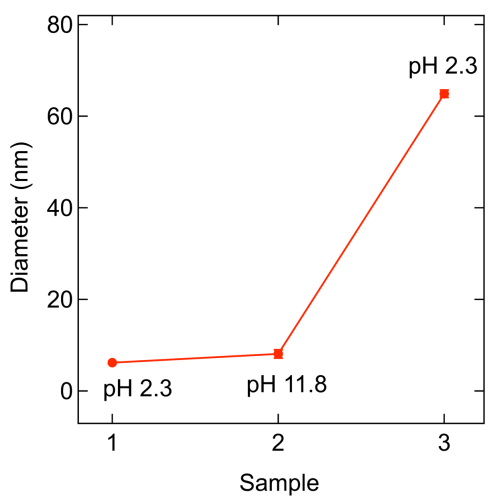

Figure S8: (A) Solid Lines: The spectrum of as photolyzed pH 2.14 uc- $\mathrm{TiO}_{2}{ }^{R}(1)$ is shown in red along with spectra recorded after consecutive $\mathrm{pH}$ changes: $\mathrm{pH} 11.89$ : (2, orange, under blue trace), $\mathrm{pH} 2.13$ (3, green), and $\mathrm{pH} 11.97$ (4, blue). Dashed Lines: The spectrum of each colloid after oxidation with air. Spectra are normalized to account for dilutions of the stock $u c-\mathrm{TiO}_{2}{ }^{R}$ solutions. (B) The absorbance at 600 and $790 \mathrm{~nm}$ as a function of successive $\mathrm{pH}$ changes. (C) The hydrodynamic diameter of uncapped $u c-\mathrm{TiO}_{2}$ nanoparticles as a function of subsequent $\mathrm{pH}$ changes. Before DLS measurements, the colloids were diluted 10-fold with either $\mathrm{pH} 2.3$ or $\mathrm{pH} 11.8 \mathrm{H}_{2} \mathrm{O}$. In this particular experiment, agglomeration occurred upon re-acidification (in contrast to the data in Figure $\mathrm{S} 5$ above).

The spectral differences of the acidic colloids before and after $\Delta \mathrm{pH}$ (the increased absorbance near the $\mathrm{TiO}_{2}$ band edge of the red and green trace in Figure S8A are consistent with NP agglomeration in this experiment. The agglomeration of reacidified colloids was confirmed with dynamic light scattering which shows that the average hydrodynamic diameter of uncharged nanoparticles of acidic colloids after a $\mathrm{pH}$ change were an order of magnitude larger than the preceding acidic and basic colloids (Figure S8C). In contrast, the experiment shown in Figure S5 showed little agglomeration, indicating the sensitivity of uc$\mathrm{TiO}_{2}{ }^{R}$ upon cycling through neutral $\mathrm{pH}$ (especially upon acidification with $\mathrm{HCl}$ ). These $\Delta \mathrm{pH}$ experiments required careful attention to detail and precise technique, as described above, to maintain NP stability through $\mathrm{pH}$ cycling.

Citrate Capped NPs: The increased stability of $c-\mathrm{TiO}_{2}$ allowed for the examination of $\mathrm{pH}$ effects over a wider $\mathrm{pH}$ range $(\mathrm{pH}>3.5)$. While the optical changes of $u c-\mathrm{TiO}_{2}{ }^{R}$ occurred instantaneously with oscillation between low to high $\mathrm{pH}$, the changes in the citrate capped $c-\mathrm{TiO}_{2}{ }^{R}$ optical spectrum with $\mathrm{pH}$ were slow, occuring over $\sim 5$ hours. The spectra of $c-\mathrm{TiO}_{2}{ }^{R}$ as a function of $\mathrm{pH}$ is shown in Figure S9A. Although the spectral shape and intensity of the reduced colloid is relatively consistant below $\mathrm{pH} 7$, upon further basification, the $\mathrm{c}-\mathrm{TiO}_{2}{ }^{R}$ absorbance increases in a linear fashion as a function of $\mathrm{pH}$ (Figure S9B). Interestingly, the spectral shape and molar absorptivties of uncapped and citrate capped $\mathrm{TiO}_{2}{ }^{R}$ are similar at very high and low $\mathrm{pH}$ values. 
A

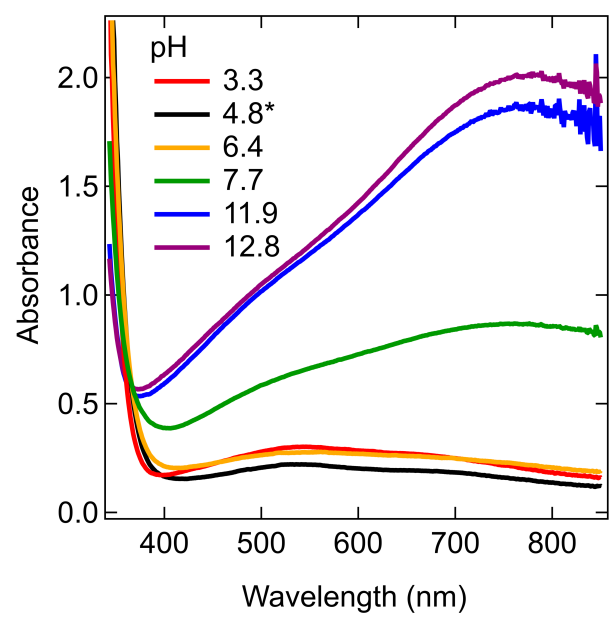

B

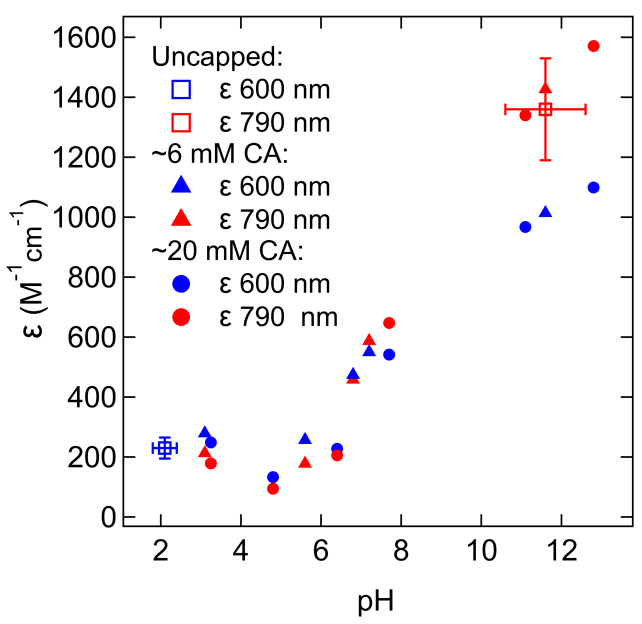

Figure S9: (A) The volume corrected spectra of $c-\mathrm{TiO}_{2}{ }^{R}(20 \mathrm{mM}$ citric acid, pre photolysis) as a function of $\mathrm{pH}$. The $\mathrm{pH}$ of as photolyzed $c-\mathrm{TiO}_{2}{ }^{R}(\mathrm{pH} 4.8)$ was adjusted via addition of aqueous $\mathrm{HCl}$ or $\mathrm{NMe}_{4} \mathrm{OH}$ solutions. (B) The molar extinction coefficient $(\varepsilon)$ at 600 and $790 \mathrm{~nm}$ of uncapped (squares), and citrate capped (6 and $20 \mathrm{mM}) \mathrm{TiO}_{2}{ }^{R}$ as a function of $\mathrm{pH}$. 


\section{S3.2 $\Delta \mathrm{pH}$ of $c-\mathrm{TiO}_{2}{ }^{R}$ Colloids at Low and High pH}

The change in $\mathrm{pH}$ of ET vs. PCET oxidized samples was assessed with $c-\mathrm{TiO}_{2}{ }^{R}$ at low and high $\mathrm{pH}$. The $c-\mathrm{TiO}_{2}$ colloid ( $\mathrm{pH} 5.3,5.6 \mathrm{mM}$ citric acid, $\sim 26 \mu \mathrm{M} \mathrm{NP}$ ) was photochemically reduced, resulting in the generation of $\sim 0.75 \mathrm{mM}$ additional electrons and a slight increase in the colloid $\mathrm{pH}$ to 5.5 . One half of the $c-\mathrm{TiO}_{2}{ }^{R}$ colloid, was treated with base $\left(\mathrm{NMe}_{4} \mathrm{OH}\right)$ to give a final $\mathrm{pH}$ of 9.7 while the other was left as prepared. As shown in Scheme S2, the as prepared and basic NPs were divided into 3 separate aliquots and oxidized by either $\mathrm{KI}_{3}\left(11.7 \mathrm{mM} \mathrm{I}_{2}, 30 \mathrm{mM} \mathrm{KI}\right)$, 4-MeO-TEMPO $(15.16 \mathrm{mM})$, or $\mathrm{O}_{2}$. The as prepared $C-\mathrm{TiO}_{2}{ }^{R}$ oxidations by 4-MeO-TEMPO and $\mathrm{O}_{2}$ gave similar $\mathrm{pH}$ values: 5.5 and 5.4 , respectively. The basic $c-\mathrm{TiO}_{2}{ }^{R}$ oxidations by 4-MeO-TEMPO and $\mathrm{O}_{2}$ resulted in $\mathrm{pH} 9.4$ and 9.2 solutions. The $\mathrm{pH}$ of colloids oxidized by $\mathrm{Kl}_{3}$ were $\sim 0.4-0.8 \mathrm{pH}$ units more acidic than the $\mathrm{O}_{2}$ and 4-MeO-TEMPO oxidized samples. All six reactions and the resulting $\mathrm{pH}$ values are outlined in Scheme $\mathrm{S} 2$.

Scheme S2: The photochemical reduction $(h v)$ and oxidation of $c-\mathrm{TiO}_{2}{ }^{\mathrm{R}}$ by (i) $\mathrm{KI}_{3}$, (ii) 4-MeO-TEMPO, and (iii) $\mathrm{O}_{2}{ }^{*}$

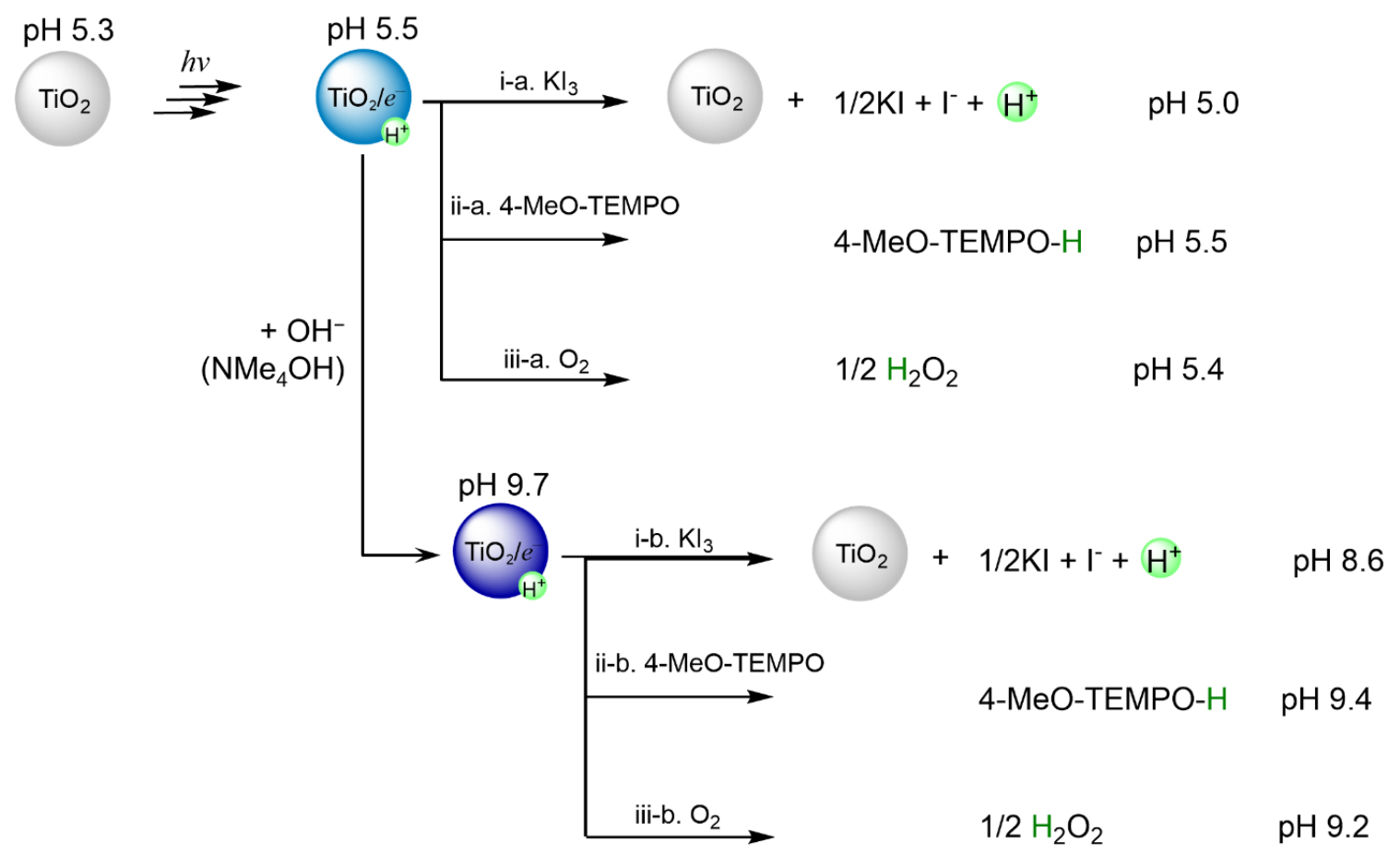

* The concentration of additional electrons in $c-\mathrm{TiO}_{2}{ }^{\mathrm{R}}$ was determined via optical titrations with $\mathrm{Kl}_{3}$ (Section S2.2). The pH 5.5 and 9.7 colloids contained 0.78 and $0.72 \mathrm{mM} e^{-}$respectively. The basic, $\mathrm{pH} 9.7$ colloid was prepared via addition of aqueous $\mathrm{NMe} 4 \mathrm{OH}(\mathrm{pH} 13.4)$ to $c-\mathrm{TiO}_{2}{ }^{R}$ ( $4 \%$ by volume dilution). The prephotolysis concentrations of citric acid in the colloids were $5.63 \mathrm{mM}(\mathrm{pH} 5.5)$ and $5.40 \mathrm{mM}(\mathrm{pH} 9.7)$.

Given the complex buffering capacity of the colloid suspensions, extracting $\Delta\left[\mathrm{H}^{+}\right]$from the $\Delta \mathrm{pH}$ of the ET and PCET oxidized colloids it not trivial. This complexity is explored in the next sections. 


\section{S3.3 c- $\mathrm{TiO}_{2}$ Buffering Capacity}

To explore the buffering capacity of the $c-\mathrm{TiO}_{2}$ colloids, parallel base titrations of $6 \mathrm{mM}$ citric acid solutions with and without $30 \mu \mathrm{M} \mathrm{TiO}_{2}$ nanoparticles were performed (Figure S10). At $\mathrm{pH}<7$, the titration curves of the colloid (NP + citric acid) and solution (citric acid only) are almost parallel. Above pH 7 , however, the colloid titration exhibits a much shallower dependence on the volume of base added than the citric acid solution. The similarity of the titration curves below pH 7 suggests that citric acid is the dominant buffer in both the solution and colloid within this $\mathrm{pH}$ range. The steep increase in the $\mathrm{pH}$ of the citric acid solution above $\mathrm{pH} 7$ is consistent with the third and final citric acid $\mathrm{p} K_{\mathrm{a}}$ of $6.39 .{ }^{21}$ In contrast, the shallower dependence of the colloid $\mathrm{pH}$ on the volume of base above neutral $\mathrm{pH}$ suggests that $\mathrm{TiO}_{2}$ has a significant buffering capacity in this $\mathrm{pH}$ range.

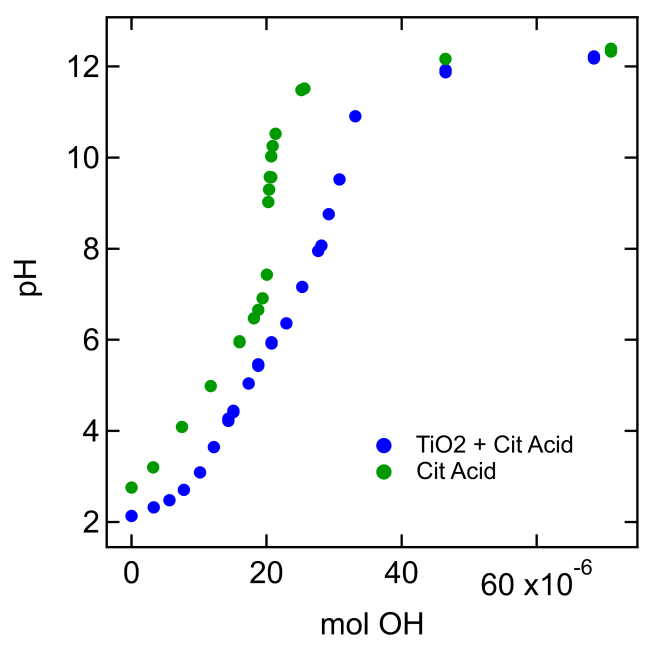

Figure S10: The $\mathrm{pH}$ of a $6 \mathrm{mM}$ citric acid solution (1.5 mL green) and a $6 \mathrm{mM}$ citric acid, $\sim 30 \mu \mathrm{M} \mathrm{c}-\mathrm{TiO}_{2} \mathrm{NP}$ colloid $\left(1.5 \mathrm{~mL}\right.$ blue) upon base $\mathrm{NMe}_{4} \mathrm{OH}(0.069 \mathrm{mM})$ titration.

The results of these titrations suggest that simulations of a model citric acid solution ${ }^{22}$ will not accurately predict $\Delta \mathrm{pH}$ of colloids above $\mathrm{pH} 7$ where the titrations curves of the colloid and solution diverge (Figure S10). Because a model citric acid solution does not account for the additional buffering capacity of $\mathrm{TiO}_{2}$ NPs, simulations of experimental $\Delta \mathrm{pH}$ 's above $\mathrm{pH} 7$ with a citric acid model will systematically underrepresent $\Delta\left[\mathrm{H}^{+}\right]$. This analysis is consistent with inconsistencies in the simulations of the $\Delta \mathrm{pH}$ between the ET and PCET reactions shown in Scheme S2 at different $\mathrm{pH}$ values. ${ }^{22}$

\section{S3.4 Simulations of $\Delta \mathrm{pH}$ in $\mathrm{c}-\mathrm{TiO}_{2}{ }^{R}$ colloids}

To better understand the cause of $\mathrm{pH}$ changes observed with $\mathrm{c}-\mathrm{TiO}_{2}, \mathrm{pH}$ simulations were performed using CurTiPlot, freeware produced by Ivano Gebhardt Rolf Gutz. ${ }^{23}$ These simulations evaluated the $\mathrm{pH}$ increases associated with photochemical reduction of $\mathrm{TiO}_{2}$ (photooxidation of citric acid) and solution $\mathrm{pH}$ decreases associated with oxidation of $c-\mathrm{TiO}_{2}{ }^{\mathrm{R}}$. 
Scheme S3: The $2 e^{-}$and $2 \mathrm{H}^{+}$oxidation of citric acid, initiated by a $\mathrm{TiO}_{2}$-based, photo-generated exciton hole $\left(h^{+}\right)$, results in the formation of 3-OGA and $\mathrm{CO}_{2}$. The spontaneous decarboxylation of 3-OGA gives two more equivalent of $\mathrm{CO}_{2}$. $\mathrm{CO}_{2}$ forms carbonic acid $\left(\mathrm{H}_{2} \mathrm{CO}_{3}\right)$, bicarbonate and carbonate in water.

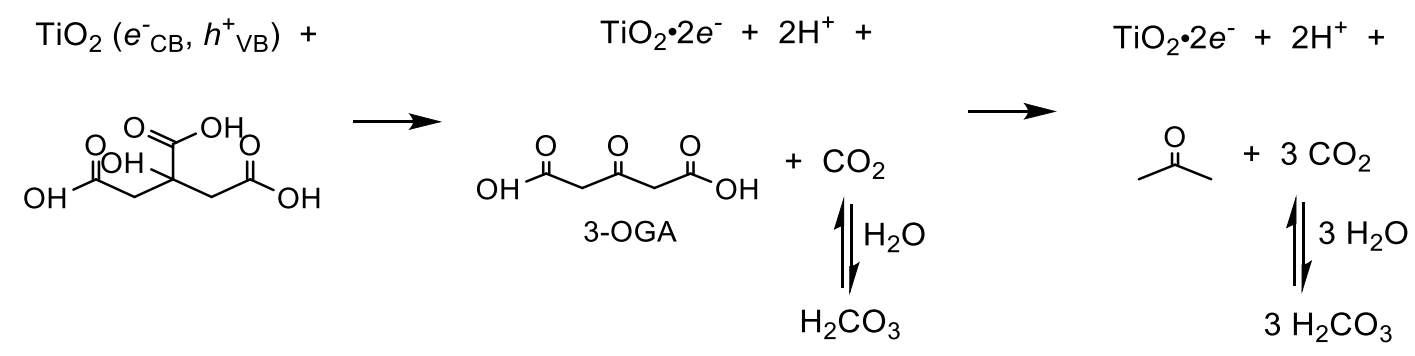

\section{S3.4.1 $\Delta \mathrm{pH}$ Simulations for $c-\mathrm{TiO}_{2}$ Photochemical Reduction}

The simulations of the colloid $\mathrm{pH}$ changes upon photochemical reduction of $\mathrm{c}-\mathrm{TiO}_{2}$ and the accompanying photochemical oxidation (consumption) of citric acid was performed to provide insights into the buffering of photolysis by-products. For pre-photolysis samples, the $\mathrm{HCl}$ concentration was determined based on the initial solution $\mathrm{pH}$ and the citric acid concentration added to solution ([citric acid] $]_{\text {init }}$ ) was assessed. As shown in Scheme $\mathrm{S} 3$, the $2 \mathrm{e}^{-}$and $2 \mathrm{H}^{+}$oxidation of citric acid results in the formation of either (1) 3-oxoglutaric acid (3-OGA) and carbonic acid $\left(\mathrm{H}_{2} \mathrm{CO}_{3}\right)$ or (2) 3 equivalents of $\mathrm{H}_{2} \mathrm{CO}_{3}$. To determine the expected concentration of citric acid photooxidation products, the $\left[e^{-}\right]$of $c-\mathrm{TiO}_{2}{ }^{R}$ was determined and this value divided in half to account for the 2:1 ratio of $\mathrm{TiO}_{2}{ }^{R}$ to citric acid photooxidation. Simulations with the two different possible photooxidation product routes were performed to predict the final solution $\mathrm{pH}$, and these values were compared to experimentally measured values (Table S1).

The simulated $\mathrm{pH}$ values increase only slightly upon partial conversion of citric acid to 3-OGA and 1 $\mathrm{H}_{2} \mathrm{CO}_{3}$ (case 1 above). This maintenance of the simulated $\mathrm{pH}$ values is not surprising given that the combined 3-OGA and $\mathrm{H}_{2} \mathrm{CO}_{3} \mathrm{pK}_{\mathrm{a}}$ values are similar to citric acid $\mathrm{p} K_{\mathrm{a}}$ 's. Upon partial conversion of citric acid to 3 equivalents of carbonic acid (case 2), the simulated pH increases by $\sim 0.2-0.3 \mathrm{pH}$ units. The experimentally measured $\mathrm{pH}$ values of $\mathrm{TiO}_{2}{ }^{R}$ colloids after oxidation by PCET oxidants (4-MeO-TEMPO or $\mathrm{O}_{2}$ ) are almost equivalent to the $\mathrm{pH}$ values simulated by the conversion of photo-oxidized citric acid to 3 equivalents $\mathrm{H}_{2} \mathrm{CO}_{3}$. This result strongly suggests that the increase in the $\mathrm{c}-\mathrm{TiO}_{2} \mathrm{pH}$ upon photolysis and PCET oxidation likely results from the consumption of the triprotic citric acid. The very slight acidification of the experimental $\mathrm{pH}$ values relative to those simulated by the conversion of photo-oxidized citric acid to 3 $\mathrm{H}_{2} \mathrm{CO}_{3}$, may indicate that not all of the 3-OGA photooxidation product is converted to $\mathrm{CO}_{2}$ and subsequently $\mathrm{H}_{2} \mathrm{CO}_{3}$ under the conditions studied here. It is possible other influences such as citrate surface ligation, the uptake of protons by $\mathrm{c}-\mathrm{TiO}_{2}{ }^{\mathrm{R}}$, or other side reactions during the photochemical reduction/oxidation also influence these $\mathrm{pH}$ changes, but those factors are not accounted for in these simulations. 
Table S1: The measured $\mathrm{pH}$ values of $c-\mathrm{TiO}_{2}$ colloids before photolysis and after PCET oxidation by $\mathrm{O}_{2}$ or 4-MeO-TEMPO. The simulated $\mathrm{pH}$ values resulting from the decrease in [citric acid] and the increase in the photooxidation product (either 3-OGA and $\mathrm{H}_{2} \mathrm{CO}_{3}$ or $3 \mathrm{H}_{2} \mathrm{CO}_{3}$ ) are also listed in the table below.

\begin{tabular}{|c|c|c|c|}
\hline \multicolumn{2}{|c|}{ Measured pH } & \multicolumn{2}{c|}{ Simulated pH } \\
\hline Pre- $\boldsymbol{h} \boldsymbol{v}$ & PCET Oxidized & $\begin{array}{c}\text { PCET Oxidized } \\
\text { 3-OGA, } \mathbf{H}_{2} \mathbf{C O}_{3}\end{array}$ & $\begin{array}{c}\text { PCET Oxidized } \\
\text { 3 } \mathbf{H}_{2} \mathbf{C O}_{3}\end{array}$ \\
\hline 5.29 & 5.61 & 5.29 & 5.69 \\
\hline 5.23 & 5.51 & 5.25 & 5.57 \\
\hline 5.44 & 5.51 & 5.45 & 5.67 \\
\hline
\end{tabular}

\section{S3.4.2 $\Delta \mathrm{pH}$ Simulations for $\mathrm{c}-\mathrm{TiO}_{2}{ }^{R}$ Oxidation}

The simulations of the $\Delta \mathrm{pH}$ of $C-\mathrm{TiO}_{2}{ }^{R}$ oxidized by ET vs. PCET oxidants were performed in two ways. In the first, the $\Delta\left[\mathrm{H}^{+}\right]$between the ET and PCET oxidized colloid was assumed equal to the total $\left[\mathrm{e}^{-}\right]$ measured in the colloid. The assumed $\Delta\left[\mathrm{H}^{+}\right]$was then added to the simulated solution of citric acid and photo-oxidation products. The resulting (simulated) $\Delta \mathrm{pH}$ was compared to the experimental $\Delta \mathrm{pH}$. In the second, less discussed method, the experimental $\triangle \mathrm{pH}$ between ET and PCET oxidized colloids was simulated to determined $\Delta\left[\mathrm{H}^{+}\right]$.

In the first method, three different simulations $(\mathrm{A}-\mathrm{C})$ were utilized to evaluate $\Delta\left[\mathrm{H}^{+}\right]$with the different possible citric acid photooxidation products. The initial parameters of the pre-photolysis samples included $\mathrm{NMe}_{4} \mathrm{OH}$ and citric acid. Per the discussion in Section S3.4.1, the ratio of photooxidized citric acid to $\mathrm{TiO}_{2}-$ based electrons was assumed 1:2 and the concentration of photooxidation products were subtracted from the initial concentration of citric acid. The possible photooxidation products were assumed to be 3-OGA and $\mathrm{H}_{2} \mathrm{CO}_{3}$ (Simulation $A$ ), 3 equivalents of $\mathrm{H}_{2} \mathrm{CO}_{3}$ (Simulation $B$ ), or were not accounted for (Simulation C). Next, the $\Delta\left[\mathrm{H}^{+}\right]$(assumed equal to the total concentration of photochemically generated additional electrons in the colloid) was added and the simulation was assessed. 


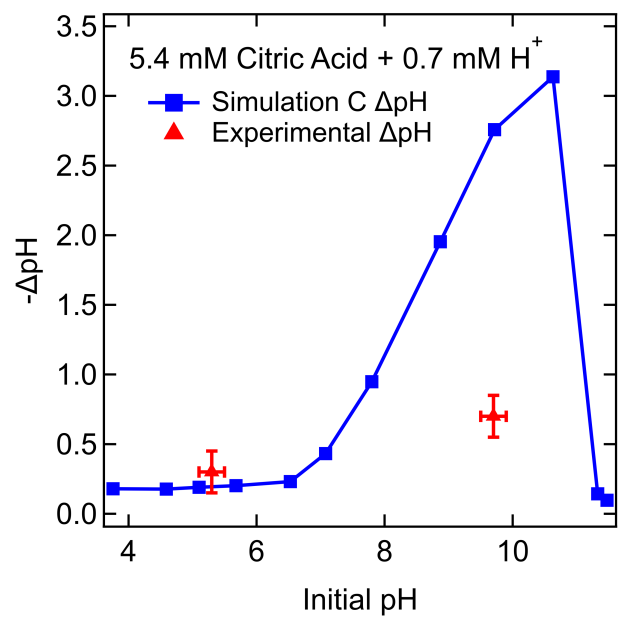

Figure S11: The simulated (Simulation $\mathrm{C}$ ) acidification $(-\Delta \mathrm{pH})$ of a $5.4 \mathrm{mM}$ solution of citric acid upon addition of $0.7 \mathrm{mM} \mathrm{H}^{+}$(blue). The experimental $-\Delta \mathrm{pH}$ of the $\mathrm{KI}_{3}$ oxidation reactions presented in Scheme S2 have been included for reference (red).

Figure $\mathrm{S} 11$ shows the colloid acidification $(-\Delta \mathrm{pH})$ from Simulation $\mathrm{C}$, resulting from the addition of 0.7 $\mathrm{mM} \mathrm{H}^{+}$to a solution of $5.4 \mathrm{mM}$ citric acid as a function of initial solution $\mathrm{pH}$ (x-axis). According to this simulation, the largest solution acidifications $(-\Delta \mathrm{pH} \approx 3)$ are expected when the initial solution $\mathrm{pH}$ is outside the buffering range of citric acid, $\mathrm{pH}>8$ and $<10.5$. Assuming a $1: 1$ ratio of photo-generated $\mathrm{H}^{+}$and $\mathrm{e}^{-}$, this simulation mirrors the [citric acid] init and the assumed $\Delta\left[\mathrm{H}^{+}\right]$of the $c-\mathrm{TiO}_{2}{ }^{R} \mathrm{Kl}_{3}$ oxidation experiments presented in Scheme S2 (Figure S11, red markers). The simple simulation (C) of the colloid as a solution of citric acid is consistent with the $\Delta \mathrm{pH}$ observed upon $\mathrm{Kl}_{3}$ oxidation of the $\mathrm{pH} 5.5 \mathrm{c}-\mathrm{TiO}_{2}{ }^{R}$ colloid (Scheme $\mathrm{S} 2$, i-a). However, the experimental $\Delta \mathrm{pH}$ of the $\mathrm{Kl}_{3}$ oxidized $\mathrm{pH} 9.7 c-\mathrm{TiO}_{2}{ }^{R}$ colloid is $>2 \mathrm{pH}$ unit smaller than the $\Delta \mathrm{pH}$ predicted by the simulation (Scheme $\mathrm{S} 2, \mathrm{i}-\mathrm{b}$ ).

The discrepancy between the simulations and the experimental results stems from the large buffering capacity of the $c-\mathrm{TiO}_{2}$ colloid when $\mathrm{pH}>7$. Base titrations with $\mathrm{NMe}_{4} \mathrm{OH}$ were performed to compare the buffering capacity of $c-\mathrm{TiO}_{2}$ and of a citric acid solution of similar concentration (Figure S12). The sample with both $\mathrm{TiO}_{2} \mathrm{NPs}$ and citric acid buffer showed a shallower dependence of $\mathrm{pH}$ on added base than the solution of only citric acid. This difference is most prominent above $\mathrm{pH} \mathrm{7,} \mathrm{where} \mathrm{citric} \mathrm{acid} \mathrm{is} \mathrm{completely}$ deprotonated. The enhanced buffering capacity of the colloid reflects the amphoteric nature of the $\mathrm{TiO}_{2}$ surface, which contains a variety of acid/base groups. ${ }^{10,24-26}$

Because a model citric acid solution (with or without photo-oxidation products) does not account for the additional buffering capacity of $\mathrm{TiO}_{2} \mathrm{NPs}$ above $\mathrm{pH}$, the simulated addition of some $\Delta\left[\mathrm{H}^{+}\right]$to a model solution of citric acid systematically overestimated the $\triangle \mathrm{pH}$ between ET and PCET oxidized colloids in the high $\mathrm{pH}$ range (Figure S11). Working backwards, matching the simulated $\Delta \mathrm{pH}$ to the experimental $\Delta \mathrm{pH}$, systematically gives lower $\Delta\left[\mathrm{H}^{+}\right]$. This discrepancy is seen clearly in Figure $\mathrm{S} 12$, where the simulated (A through $\mathrm{C}$ ) and experimental acid titration of an $\mathrm{O}_{2}$ oxidized $\mathrm{TiO}_{2}{ }^{R}$ colloid are plotted vs. $\mathrm{mol} \mathrm{H}^{+}$. The $\mathrm{TiO}_{2}$ colloid displays the shallowest dependence on $\mathrm{mol} \mathrm{H}^{+}$and has the largest $\mathrm{pH}$ buffering capacity. Relatively, the simulated acid titrations exhibit a steep dependence on $\mathrm{mol}^{+}$. The small difference between simulations $A$ through $\mathrm{C}$ can be explained by the relative concentrations of carbonic acid $\left(\mathrm{p} K_{\mathrm{a}}=\sim 10.3\right.$ and 
6.4) between the simulations. Overall, while these simulations were informative, they were not able to reproduce the experimental buffering capacity of the colloid solutions. This highlights the complexity of these $\mathrm{TiO}_{2}$ systems and these types of $\mathrm{pH}$ analyses.

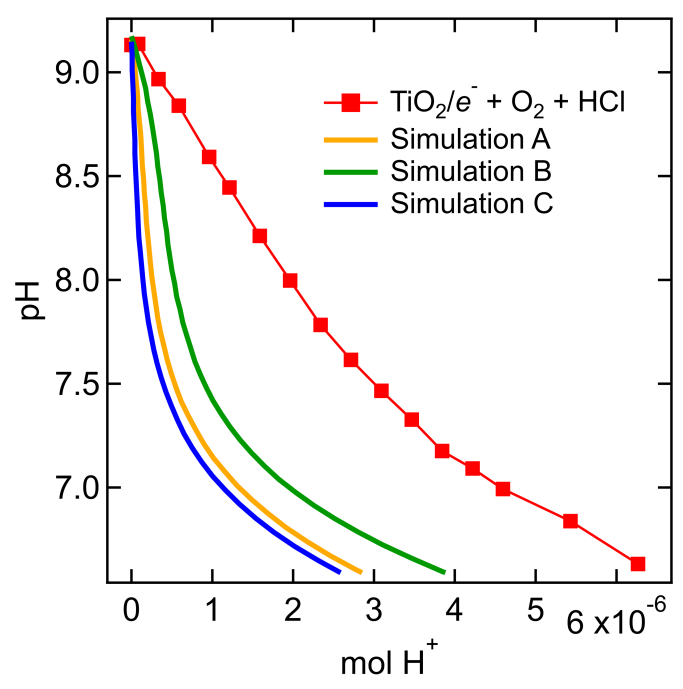

Figure S12: The acid titration ( $8.4 \mathrm{mM} \mathrm{HCl}$, aqueous) of an $\mathrm{O}_{2}$ oxidized $c-\mathrm{TiO}_{2}{ }^{R}$ colloid containing $5.52 \mathrm{mM}$ citric acid pre-photolysis and $1.15 \mathrm{mM}$ additional electrons post-photolysis. Simulation A parameters: 4.95 $\mathrm{mM}$ citric acid, $0.58 \mathrm{mM}$ 3-OGA, $0.58 \mathrm{mM} \mathrm{H}_{2} \mathrm{CO}_{3}$. Simulation B parameters: $4.95 \mathrm{mM}$ citric acid, $0 \mathrm{mM} 3-$ OGA, $1.73 \mathrm{mM} \mathrm{H}_{2} \mathrm{CO}_{3}$. Simulation C parameters: $5.52 \mathrm{mM}$ citric acid, $0 \mathrm{mM}$ 3-OGA, $0 \mathrm{mM} \mathrm{H}_{2} \mathrm{CO}_{3}$.

\section{S3.5 Empirical Quantification of Coupled $\mathrm{H}^{+}$in $\mathrm{TiO}_{2}{ }^{R} \mathrm{NPs}$ :}

As detailed in the manuscript (Scheme 1, Figure 2), the addition of $\mathrm{Kl}_{3}$ to $\mathrm{TiO}_{2}{ }^{\mathrm{R}}$ resulted in a decrease in solution $\mathrm{pH}$. This decrease in $\mathrm{pH}$ was larger for $\mathrm{TiO}_{2}{ }^{\mathrm{R}}$ oxidized with the electron transfer reagent, $\mathrm{KI}_{3}$, than for colloid solutions oxidized with PCET oxidants, 4-MeO-TEMPO and $\mathrm{O}_{2}$ (air). Below are the details of another experiment probing these $\mathrm{pH}$ changes with respect to $\Delta\left[\mathrm{H}^{+}\right]$.

A batch of $c-\mathrm{TiO}_{2}$ was photochemically reduced, equilibrated, and separated into aliquots $(\mathrm{pH} 8.10$, $0.46 \mathrm{mM} \mathrm{e}^{-}$). The colloid solutions were fully oxidized using $\mathrm{Kl}_{3}$, 4-MeO-TEMPO, and $\mathrm{O}_{2}$ (air) and the final $\mathrm{pH}$ was measured (Scheme S4). The solution oxidized with $\mathrm{Kl}_{3}$ had a final $\mathrm{pH}$ of 7.37 , while the PCET oxidants 4-MeO-TEMPO and $\mathrm{O}_{2}$ had final $\mathrm{pH}$ values of 7.80 and 7.79 , respectively. To account for $\mathrm{TiO}_{2}$ and citrate buffering and to empirically determine the $\Delta\left[\mathrm{H}^{+}\right], 9.2 \mathrm{mM} \mathrm{HCl}$ was titrated into the PCET solutions (Figure S13). The addition of $0.41 \mathrm{mM}$ of $\mathrm{HCl}$ to both the 4-MeO-TEMPO and $\mathrm{O}_{2}$ solutions was required to match the $\mathrm{KI}_{3}$ solution $\mathrm{pH}$. Overall, the ratio of protons to electrons released in this experiment was 0.89 : 1.00, which was slightly less than the 1.15:1.00 ratio in Manuscript Figure 2 but is very close to a stoichiometry of $\mathrm{TiO}_{2} \bullet \mathrm{e}^{-}, \mathrm{H}^{+}$. 
Scheme S4: Oxidation of $c-\mathrm{TiO}_{2}{ }^{R}$ by $\mathrm{Kl}_{3}, 4-\mathrm{MeO}-\mathrm{TEMPO}$, and $\mathrm{O}_{2}$ followed by acid titrations of the PCET oxidized colloids with $\mathrm{HCl}^{a}$

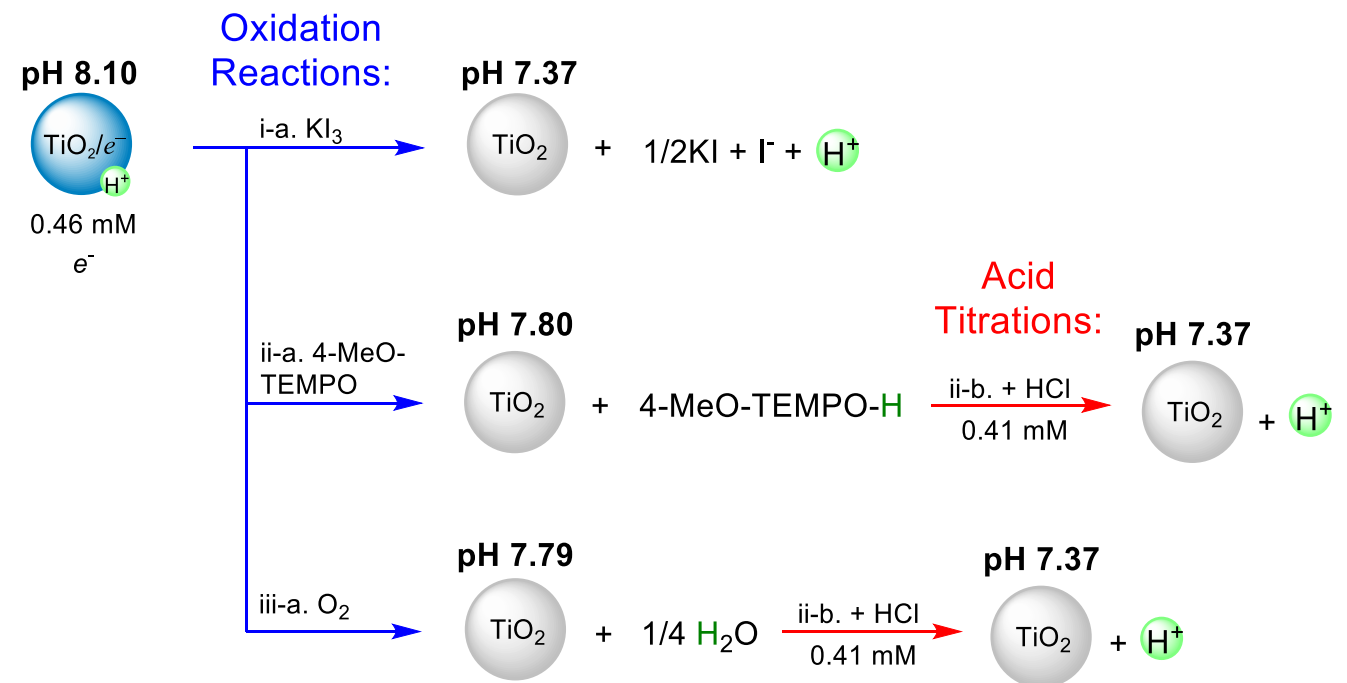

${ }^{a}$ Additional electrons in photochemically reduced $c-\mathrm{TiO}_{2}{ }^{R}(\mathrm{pH} 8.10)$ were quantified via an optical titration with $\mathrm{KI}_{3}\left(5.4 \mathrm{mM} \mathrm{I}_{2}, 29.3 \mathrm{mM} \mathrm{KI}\right)$. Acid titration data are plotted in Figure S13.

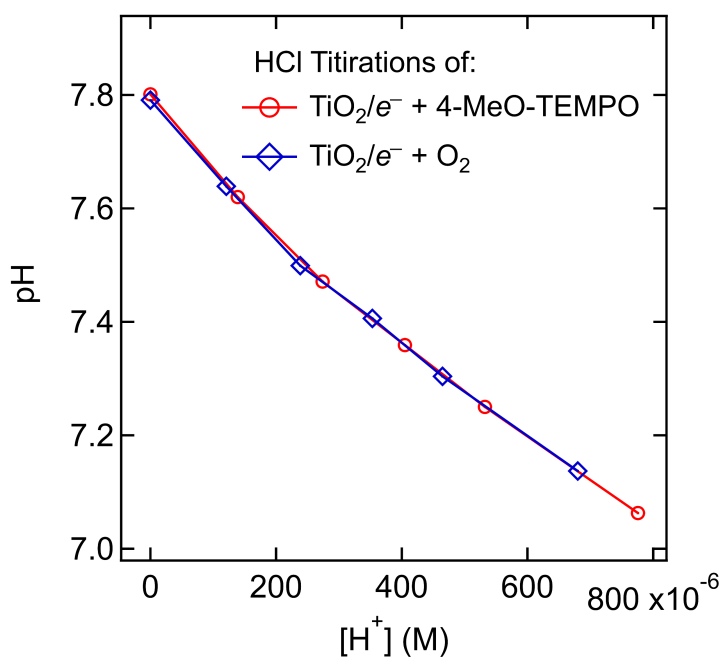

Figure S13: Acid $\left(9.2 \mathrm{mM} \mathrm{HCl}\right.$ in $\mathrm{H}_{2} \mathrm{O}$ ) titrations of PCET oxidized $c-\mathrm{TiO}_{2}$ colloids. See Scheme $\mathrm{S} 4$ for details. 


\section{S3.6 Comprehensive $\Delta \mathrm{pH}$ of $c-\mathrm{TiO}_{2}{ }^{R} \mathrm{NPS}$}

The $\mathrm{pH}$ values of all $\mathrm{c}-\mathrm{TiO}_{2}$ samples before and after photolysis and upon oxidation with various oxidants are listed in Table S2 below.

Table S2: $\mathrm{pH}$ of $\mathrm{TiO}_{2}$ colloids before $\left(c-\mathrm{TiO}_{2}\right)$ and after $\left(c-\mathrm{TiO}_{2}{ }^{R}\right)$ photolysis and upon oxidation with 4-MeOTEMPO (TEMPO), $\mathrm{O}_{2}$, and $\mathrm{KI}_{3}$.

\begin{tabular}{|c|c|c|c|c|}
\hline $\mathrm{TiO}_{2}$ & $\mathrm{TiO}_{2} / e$ & \multicolumn{2}{|c|}{$\begin{array}{c}\text { PCET Oxidant } \\
\left(\mathrm{X}^{\circ}\right)\end{array}$} & $\begin{array}{c}\text { ET Oxidant } \\
\text { Ox }\end{array}$ \\
\hline $\mathrm{TiO}_{2}$ & $\mathrm{TiO}_{2}{ }^{R}$ & + TEMPO & $+\mathrm{O}_{2}$ & $+\mathrm{KI}_{3}$ \\
\hline 5.29 & & & 5.61 & 4.83 \\
\hline \multirow[t]{3}{*}{5.23} & 5.55 & & 5.51 & 4.96 \\
\hline & & & 6.58 & 5.88 \\
\hline & 10.37 & 9.99 & 9.91 & 8.86 \\
\hline 5.44 & 5.66 & & 5.49 & \\
\hline \multicolumn{5}{|l|}{5.39} \\
\hline & 10.00 & & 9.57 & 8.53 \\
\hline \multirow[t]{2}{*}{5.44} & 6.09 & 5.69 & 5.51 & 5.07 \\
\hline & 8.55 & 8.21 & 8.10 & 7.52 \\
\hline \multirow[t]{2}{*}{5.29} & 5.46 & 5.54 & 5.40 & 4.97 \\
\hline & 9.70 & 9.42 & 9.23 & 8.58 \\
\hline
\end{tabular}




\section{S4 Redox equilibration for $c-\mathrm{TiO}_{2}$ and $u c-\mathrm{TiO}_{2} \mathrm{NPs}$}

In order to determine the non-standard reducing potential of photochemically reduced $\mathrm{TiO}_{2}$, optical spectroscopy was used to determine the reactivity of $\mathrm{TiO}_{2}{ }^{R}$ with various oxidants. Whenever possible, oxidants $(\mathrm{Ox})$ with characteristic optical signals in the reduced forms were chosen for this purpose. Although each individual oxidant will be discussing in further detail below, the general evaluation of the optical titrations was as follows:

eq S4.1 $\mathrm{TiO}_{2} \cdot \mathrm{e}^{-}, \mathrm{H}^{+}+\mathrm{Ox} \rightleftharpoons \mathrm{TiO}_{2}+\mathrm{H}^{+}$col $+\mathrm{Red}$

eq S4.2 A $\times$ Voltot $_{\text {to }}+\left(\mathrm{TiO}_{2} \cdot \mathrm{e}^{-}, \mathrm{H}^{+} \mathrm{mol}_{\text {init }} \times \varepsilon_{\mathrm{NP}}\right)-\delta\left(\mathrm{TiO}_{2} \cdot \mathrm{e}^{-}, \mathrm{H}^{+} \mathrm{mol} \times \varepsilon_{\mathrm{NP}}\right)+\delta\left(\mathrm{O} \times \mathrm{mol} \times \varepsilon_{\mathrm{Red}}\right)$

eq S4.3 $\delta=\left(\mathrm{A} \times\right.$ Voltot $_{\text {to }}-\mathrm{TiO}_{2} \bullet e^{-}, \mathrm{H}^{+}$molinit $\left.\times \boldsymbol{\varepsilon}_{\mathrm{NP}}\right) /\left(\mathrm{O} \times \mathrm{mol} \times \boldsymbol{\varepsilon}_{\mathrm{Red}}-\mathrm{TiO}_{2} \bullet e^{-}, \mathrm{H}^{+} \mathrm{mol} \times \boldsymbol{\varepsilon}_{\mathrm{NP}}\right)$

eq S4.4 A $\times$ Voltot $=$ Ox mol $\times \delta\left(\varepsilon_{\text {Red }}-\varepsilon_{\mathrm{NP}}\right)$

The electron transfer equilibration between $\mathrm{TiO}_{2}{ }^{R} \cong \mathrm{TiO}_{2} \cdot \mathrm{e}^{-}, \mathrm{H}^{+}$and various oxidant (Ox), shown in eq S4.1, was followed by optical spectroscopy. As discussed in manuscript, additional electrons in $\mathrm{TiO}_{2}{ }^{R}$ are coupled to $\mathrm{H}^{+}$. In reactions with electron only acceptors, like $\mathrm{Ox}$, the $\mathrm{H}^{+}$is transferred to the colloid $\left(\mathrm{H}^{+}\right.$col). Each absorbance spectrum along the titration of $\mathrm{TiO}_{2}{ }^{R}$ with $\mathrm{Ox}$ results from three factors: (1) the initial absorbance from $\mathrm{TiO}_{2}{ }^{R}\left(=\mathrm{TiO}_{2}{ }^{R}\right.$ molinit $\times \varepsilon_{\mathrm{NP}}$, where $\varepsilon_{\mathrm{NP}}$ is the epsilon of $\left.\mathrm{TiO}_{2}{ }^{\mathrm{R}}\right)$, (2) the absorbance loss due to $\mathrm{TiO}_{2}{ }^{R}$ oxidation, and (3) the absorbance increase due to the growth in Red. Most of the oxidants used in this study are colorless in the oxidized forms, so changes in absorbance due to the presence of $O x$ are ignored here. (However, because optical absorbance is additive, accounting for additional colored species is simple as long as the molar extinction coefficient and the relative stoichiometry of the species are known.) The three listed absorbance factors are included, in order, in eq S4.2 where $\delta$ is the fraction of added Ox that is reduced to the colored Red; $\delta \times O x$ mol $=$ Red mol, at equilbrium. To account for the dilution that occurs during the titrations, the traditional form of Beer's law is multiplied by total volume (Voltot) in eq $\$ 4.4$, and mole units are used in place of molar concentrations. Rearrangement of eq $\$ 4.2$ into eq S4.3, gives $\delta$ for each optical spectrum collected along the titration of $\mathrm{TiO}_{2}{ }^{R}$. Alternatively, $\delta$ is evaulated in eq S4.4 to the slope describing the change in A $\times$ Voltot as a function of moles Oxidant (Ox mol) added.

eq S4.5 A $\times$ Voltot $=+\left(\mathrm{TiO}_{2}{ }^{R} \mathrm{~mol}_{\text {init }} \times \boldsymbol{\varepsilon}_{\mathrm{NP}}\right)+\delta\left(\mathrm{O} \times \mathrm{mol} \times \boldsymbol{\varepsilon}_{\mathrm{Red}}\right)$

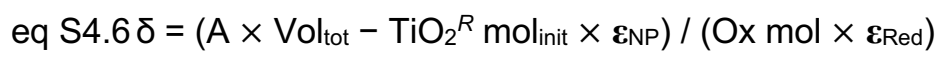

eq S4.7 A $\times$ Voltot $=\mathrm{O} \times \mathrm{mol} \times \delta\left(\varepsilon_{\text {Red }}\right)$

In cases where the epsilon of the reduced species (Red) was much greater than that of $\mathrm{TiO}_{2}{ }^{R}$, the changes in the absorbance along the titration can be equated to the growth in Red $(=\delta \times \mathrm{Ox} \mathrm{mol})$, and eq S4.2 through eq S4.4 can be simplied to eq S4.5 through eq S4.7. In these instances, the change in absorbance due to loss of $\mathrm{TiO}_{2}{ }^{R}$ is neglegable compared to the change in absorbance due to the increase in Red. 
Next, the concentrations (or moles) of Red and Ox in the titration experiments were used in conjunction with the known standard reduction potential of the Ox/Red coupled, $E^{\circ}(\mathrm{Ox} / \mathrm{Red})$, to determine the nonstandard reduction potential of $\mathrm{TiO}_{2}, E\left(\mathrm{TiO}_{2}{ }^{\mathrm{Ox} / R}\right)$, corresponding to the addition of an $\mathrm{e}^{-}$and $\mathrm{a} \mathrm{H}^{+}$to the NPs. Referenced to $1 \mathrm{M} \mathrm{H}^{+}(\mathrm{pH} 0), E_{\mathrm{pH}}$, the half-reaction potential for proton-coupled electron transfer processes, $E_{\mathrm{pH}}$, shifts by $-59 \mathrm{mV}$ per unit $\mathrm{pH} .{ }^{27}$ These data presented in the main text suggest that additional electrons in $\mathrm{TiO}_{2}$ are coupled in a 1:1 ratio to $\mathrm{H}^{+}$. Thus, the potential for proton-coupled electron transfer to $\mathrm{TiO}_{2}$, $E\left(\mathrm{TiO}_{2}{ }^{\mathrm{Ox} / R}\right)$, is expected to shift by $59 \mathrm{mV}$ per unit $\mathrm{pH}$ (eq S4.8). ${ }^{27}$ In the equilibrium shown in eq S4.1, the reduction potentials $(E)$ of the two couples are equal, and the Nernstian $(\mathrm{pH})$ dependence of $E\left(\mathrm{TiO}_{2}{ }^{\mathrm{O} / R}\right)$ is reflected in the experimental measurements of the soluble redox couple, Ox/Red (eq S4.8). Grätzel used an analogous equation (to eq S4.8) for the description of $-60 \mathrm{mV}$ per $\mathrm{pH}$ unit dependence of $\mathrm{TiO}_{2}$ reactivity with methyl viologen. ${ }^{28}$ Recall, the potential of the Ox/Red couple, $E(O x / R e d)$, is related to the standard reduction potential, $E^{\circ}(\mathrm{Ox} / \mathrm{Red})$ via the Nernst equation (eq $\left.S 4.9\right)$.

eq S4.8 $E\left(\mathrm{TiO}_{2}{ }^{\mathrm{Ox} / R}\right)=E_{\mathrm{pHO}}\left(\mathrm{TiO}_{2}{ }^{\mathrm{Ox} / R}\right)-59 \mathrm{mV} \mathrm{pH}=E(\mathrm{Ox} / \mathrm{Red})$

eq $\mathrm{S} 4.9 E(\mathrm{Ox} / \mathrm{Red})=E^{\circ}(\mathrm{Ox} / \mathrm{Red})-59 \mathrm{mV} \log \frac{[\mathrm{Red}]}{[\mathrm{Ox}]}$

The solution of eq S4.8 is commonly equated to the Fermi energy of a material or colloid in the literature. ${ }^{28-32}$ However, this is not appropriate because this equilibrium corresponds to the potential for proton-coupled electron transfer. Instead, eq $\mathbf{S 4 . 8}$ gives the reduction potential that includes contributions from both electron and proton transfers. (Potentials can be used to describe the free energy $\left(\Delta G^{\circ}=-n F E^{\circ}\right)$ of any defined reaction, not just electron transfers.) For clarity here, the reaction in question is specified in the parentheses of the potential term.

\section{S4.1 Methyl Viologen $\left(\mathrm{MV}^{2+}\right)$}

Methyl Viologen $\left(\mathrm{MV}^{2+}\right)$ was used as a $\mathrm{pH}$ independent oxidant to probe the $E\left(\mathrm{TiO}_{2}{ }^{\mathrm{Ox} / R}\right)$ of both $c-\mathrm{TiO}_{2}{ }^{R}$ and $u c-\mathrm{TiO}_{2}{ }^{R}$ nanoparticles. Methyl viologen has two reduction potentials, -0.45 and $-0.88 \mathrm{~V}$, corresponding to the one and two electron reduction to form $\mathrm{MV}^{+}$and $\mathrm{MV}^{0}$ respectively. The three oxidation states of the molecule can be distinguished by their color and intense UV-vis features (Table S3).

Table S3: The reduction potentials $\left(E^{\circ}\right)$ and optical properties of methyl viologen in its three oxidation states. The molar extinction coefficient of the dimer, $\left(\mathrm{MV}^{+}\right)_{2}$, is per equivalent of $\mathrm{MV}^{+} .{ }^{33-36}$ Reported $E^{\circ}$ are vs. $\mathrm{NHE}$.

\begin{tabular}{|c|c|c|c|c|}
\hline & $\mathrm{MV}^{2+}$ & $\mathrm{MV}^{+}$ & $\left(\mathrm{MV}^{+}\right)_{2}$ & $\mathbf{M V}^{0}$ \\
\hline Color & Colorless & Blue & Blue & Pale Yellow \\
\hline$E^{\circ}$ vs NHE & $-0.446 \mathrm{~V}$ & $-0.88 \mathrm{~V}$ & - & - \\
\hline$\varepsilon\left(\mathrm{M}^{-1} \mathrm{~cm}^{-1}\right)$ & $\begin{array}{c}\mathbf{2 5 7 n m} \\
20,700 \pm 200\end{array}$ & $\begin{array}{c}\mathbf{5 6 0} \mathbf{n m} \\
11,370 \pm 800 \\
\mathbf{3 9 6} \mathbf{n m} \\
42,100 \pm 800 \\
\mathbf{6 0 6} \mathbf{n m} \\
13,700 \pm 300\end{array}$ & $\begin{array}{c}\mathbf{5 6 0} \mathbf{~ n m} \\
11,370 \pm 800\end{array}$ & $\begin{array}{c}385 \mathrm{~nm}^{*} \\
46,000 \pm 100 \\
396 \mathrm{~nm} \\
27,000 \pm 800\end{array}$ \\
\hline
\end{tabular}


A

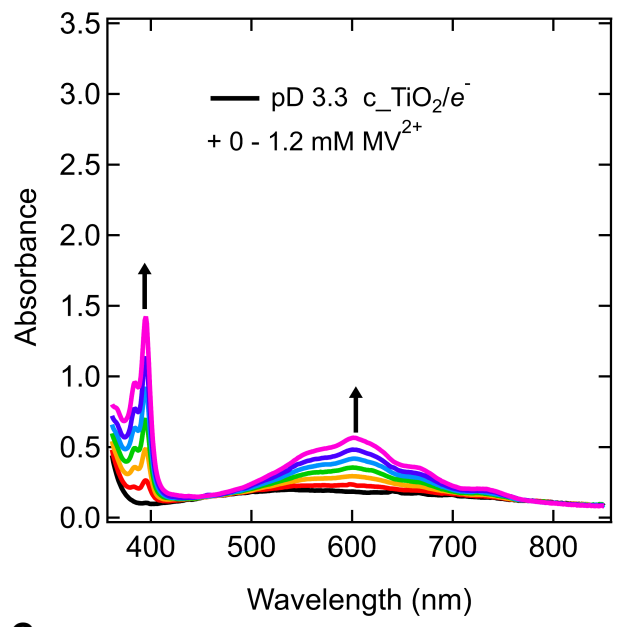

C

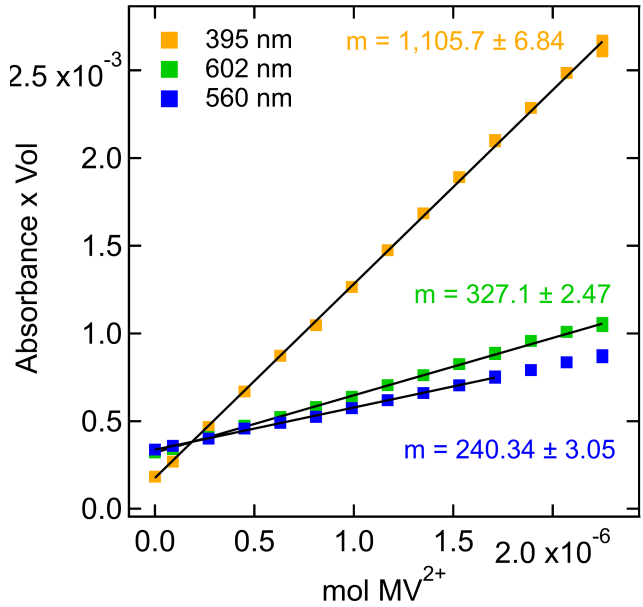

B

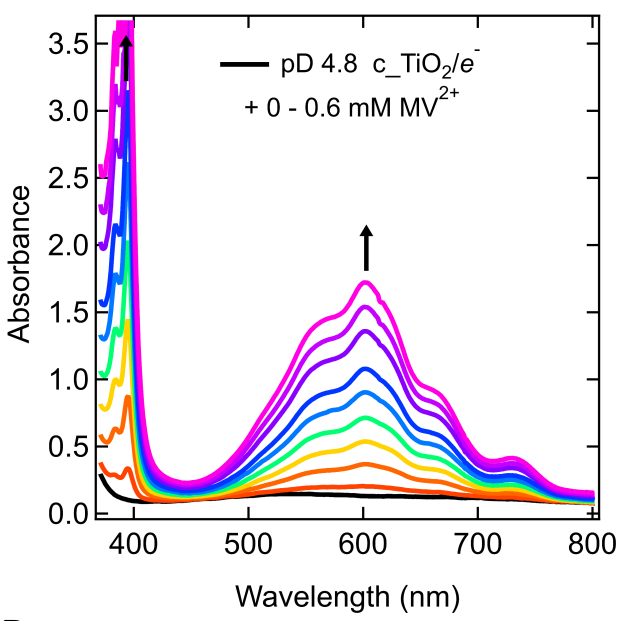

D

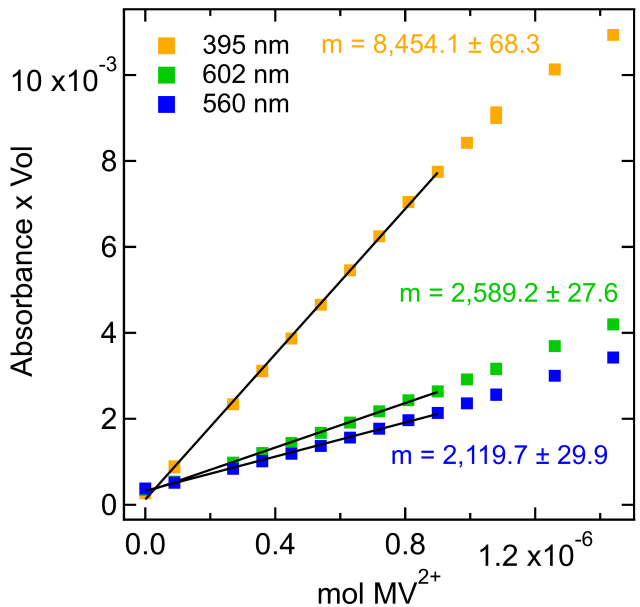

Figure S14: Optical spectra following the titration of $c-\mathrm{TiO}_{2}{ }^{R}$ (in $\mathrm{D}_{2} \mathrm{O}, 1.0 \mathrm{mM} \mathrm{e} e^{-}, \sim 30 \mu \mathrm{M} \mathrm{NPs}, 17 \mathrm{mM}$ citric acid) by $\mathrm{MV}^{2+}$ at $(\mathbf{A}) \mathrm{pD} 3.3$ and (B) pD 4.8. (C-D) The respective plots of absorbance $\times$ volume at wavelengths corresponding to the absorption peaks of $\mathrm{MV}^{+}$as a function of $\mathrm{mol} \mathrm{MV}^{2+}$. The slopes of these lines, used in eq $S 4.10$ to determine the fraction of $\mathrm{MV}^{+}(\delta)$, have been included.

The addition of $\mathrm{MV}^{2+}$ to a reduced colloid at $\mathrm{pH} 5.5$ or lower results in a deep blue coloration of the colloid and the growth of peaks at 606 and $395 \mathrm{~nm}$ on top of the broad $c-\mathrm{TiO}_{2}{ }^{R}$ optical signal (Figure S14A and $B$ ). The new optical signal is generally consistent with the distinct absorption spectrum of $1 e^{-}$reduced $\mathrm{MV}^{+}$. However, in titrations where higher concentrations of $\mathrm{MV}^{+}$were present, the 1 electron reduced dimer $\left(\left(\mathrm{MV}^{+}\right)_{2}\right)$, indicated by a new peak $\sim 800 \mathrm{~nm}$ and a blue shift in the $606 \mathrm{~nm}$ peak of $\mathrm{MV}^{+}$, was observed ${ }^{36} \mathrm{In}$ order to accurately assess the total concentration of $\mathrm{MV}^{+}$(monomer + 2dimer), the absorbance at $560 \mathrm{~nm}$, where the molar extinction coefficient of the monomer and dimer are equivalent, was probed in addition to the other $\mathrm{MV}^{+}$peaks. ${ }^{36}$ The change in the $\mathrm{MV}^{+}$absorbance peaks $(\times$volume $)$as a function of total $\mathrm{MV}^{2+}$ moles relative to the reported molar extinction coefficients of $\mathrm{MV}^{+}$gives the fraction of reduced $\mathrm{MV}^{+}$(Figure S14C and $\mathrm{D}$, eq S4.11). While only $2 \%$ of the added $\mathrm{MV}^{2+}$ is reduced by $1 \mathrm{e}^{-}$in the $\mathrm{pD} 3.3$ titration, the 
steeper growth of the $\mathrm{MV}^{2+}$ absorbance in the $\mathrm{pD} 4.8$ titration (Figure S14D) shows that $19 \%$ of the added $\mathrm{MV}^{2+}$ is reduced.

A

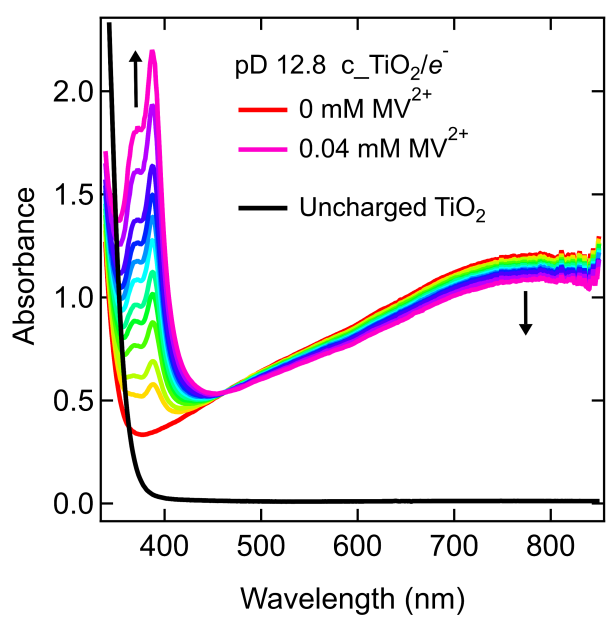

B

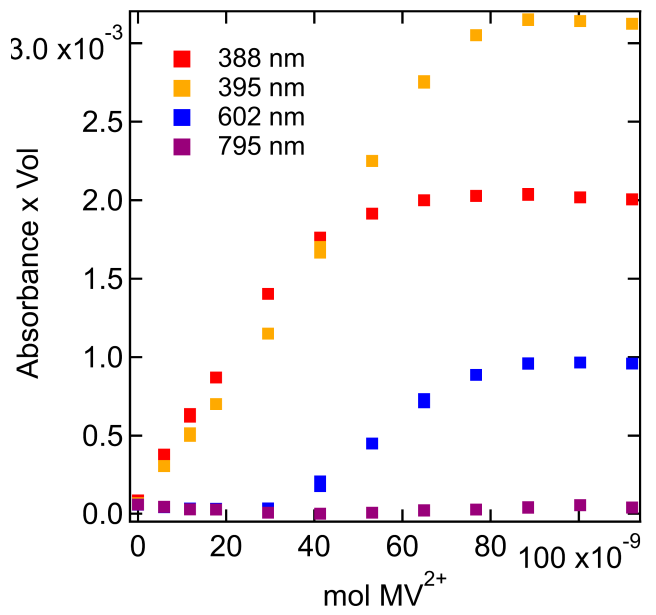

Figure S15: (A) Optical spectra following the initial (ca 10\%) titration of $c-\mathrm{TiO}_{2}{ }^{R}\left(\mathrm{pD} 12.8\right.$ in $\mathrm{D}_{2} \mathrm{O}, 1.0 \mathrm{mM}$ $e^{-}, \sim 30 \mu \mathrm{M}$ NPs, $17 \mathrm{mM}$ citric acid) by $\mathrm{MV}^{2+}$. (B) A plot of absorbance $\times$ volume vs. mol MV² for a different titration with a lower concentration of $\mathrm{TiO}_{2}$-based electrons $\left(c-\mathrm{TiO}_{2}{ }^{R}, \mathrm{pH} 11.6,36 \mu \mathrm{M} \mathrm{e} e^{-}, \sim 30 \mu \mathrm{M} \mathrm{NPs}, 5 \mathrm{mM}\right.$ citric acid) with greater than 1 equivalent of $\mathrm{MV}^{2+}$.

At $\mathrm{pH}>10$, addition of sub-stoichiometric $\mathrm{MV}^{2+}$ results in the green coloration of the colloid and growth of a new peak at $388 \mathrm{~nm}$ (Figure S15A). Further titration of $\mathrm{MV}^{2+}$ into the basic colloid eventually gives a yellow solution and the complete disappearance of the broad $c-\mathrm{TiO}_{2}{ }^{R}$ peak and blue color (Figure S15B). Beyond this point, further addition of $\mathrm{MV}^{2+}$ results in the growth of peaks at 395 and $606 \mathrm{~nm}$ and the deep blue coloration of the colloid (Figure S15B).

eq S4-10 $\quad \mathrm{TiO}_{2} \cdot 2 \mathrm{e}^{-}, 2 \mathrm{H}^{+}+\mathrm{MV}^{2+} \rightarrow \mathrm{TiO}_{2}+2 \mathrm{H}^{+}$col $+\mathrm{MV}^{0}$

The initial $\Delta \mathrm{A}_{790} \times \mathrm{Vol}$ as a function of mol MV ${ }^{2+}$ (Figure S15A) is equal to $2,800 \mathrm{M}^{-1} \mathrm{~cm}^{-1}$, which is $2 \times$ the epsilon of $\mathrm{TiO}_{2}{ }^{R}$ at $\mathrm{pH} 12.8\left(\varepsilon_{790 \mathrm{~nm}}=1,400 \pm 150 \mathrm{M}^{-1} \mathrm{~cm}^{-1}\right.$, see Figure S12), and the parallel grown in $\mathrm{A}_{388 \mathrm{~nm}}$ is consistent with the formation of $\mathrm{MV}^{0}$. Unlike the equilibrium observes in the low $\mathrm{pH}$ titrations, these initial spectral trends (Figure S15A and first half of Figure S15B) are consistent with the stoichiometric growth of $\mathrm{MV}^{0}$ and the disappearance of $2 \times \mathrm{TiO}_{2}{ }^{R}$, as per the reaction shown in eq S4-10.

The secondary increase in absorbance at $606 \mathrm{~nm}$ (second half of Figure S15B), after depletion of the $\mathrm{TiO}_{2}{ }^{\mathrm{R}}$ blue color, is consistent with the comproportionating of added $\mathrm{MV}^{2+}$ and reduced $\mathrm{MV}^{0}$ to generate $\mathrm{MV}^{+}$. Even near the endpoint (depletion of $\mathrm{TiO}_{2}{ }^{\mathrm{R}}$ ) of the titration show in Figure S15A, absorbance at 606 $\mathrm{nm}$ from $\mathrm{MV}^{+}$was not observed. The upper limit of $\left[\mathrm{MV}^{+}\right]$in this titration was approximated as $0.36 \mu \mathrm{M}$ or $1 \%$ of the total added $\mathrm{MV}^{2+}$ (assuming max $\mathrm{A}_{606 \mathrm{~nm}}$ from $\mathrm{MV}^{+}=0.005$ ) based on the spectral resolution. Using this approximation, eq $\mathrm{S} 4.8$ was used to determine a lower limit for $E\left(\mathrm{TiO}_{2}{ }^{\mathrm{O} / R}\right)$ at $\mathrm{pH} 12.8$; $E_{\mathrm{pH} 12.8}\left(\mathrm{TiO}_{2}{ }^{\mathrm{O} / R}\right) \leq-0.99 \mathrm{~V}$ vs NHE. 


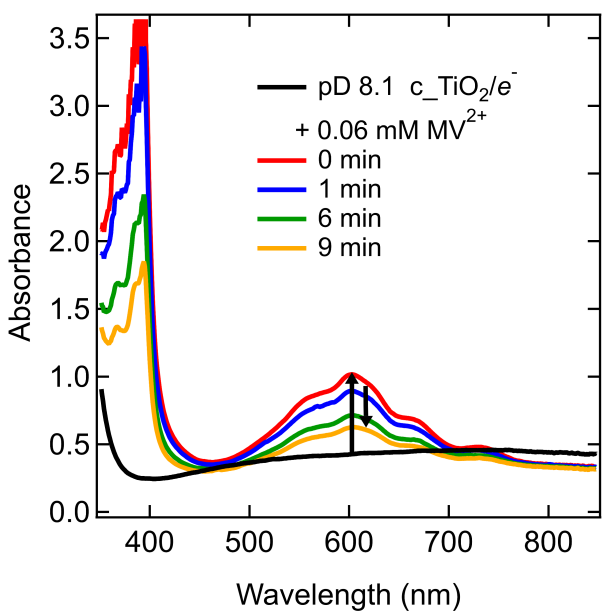

Figure S16: Optical spectra following the titration of $c-\mathrm{TiO}_{2}{ }^{R}\left(\mathrm{pD} 8.1\right.$ in $\mathrm{D}_{2} \mathrm{O}, 1.0 \mathrm{mM} e^{-}, \sim 30 \mu \mathrm{M}$ NPs, 17 $\mathrm{mM}$ citric acid) by $\mathrm{MV}^{2+}$. The arrows track the initial growth of the peaks at 606 and $395 \mathrm{~nm}$ followed by their slow disappearance over 9 minutes.

Titration of near neutral colloids with $\mathrm{MV}^{2+}$ were also performed. New peaks in the optical spectra at 606, 395 and $385 \mathrm{~nm}$ were observed (Figure S16, up arrow), consistent with the formation of both $\mathrm{MV}^{+}$and $\mathrm{MV}^{0}$. However, the new peaks steadily disappeared on the minute's timescale of the titration experiment (Figure S16, down arrow). This disappearance of the methyl viologen reduction product at near neutral $\mathrm{pH}$ likely results from the hydrogenation of $\mathrm{MV}^{0}$ to a colorless product. ${ }^{37}$ Due to these complications, reliable measurements of $E\left(\mathrm{TiO}_{2}{ }^{\mathrm{O} / R}\right)$ from $\mathrm{MV}^{2+}$ titration were not possible at $\mathrm{pH}>6$.

Titrations of $u c-\mathrm{TiO}_{2}{ }^{R}$ with $\mathrm{MV}^{2+}$ at low and high $\mathrm{pH}$ gave qualitatively similar results to the citrate capped titrations at similar $\mathrm{pH}$ values. The addition of $\mathrm{MV}^{2+}$ to a $u c-\mathrm{TiO}_{2}{ }^{R}$ colloid at $\mathrm{pH} 2.25$ resulted in the deep blue coloration of the colloid and the growth of peaks at 606 and $395 \mathrm{~nm}$ consistent with the distinct absorption spectrum of $1 \mathrm{e}^{-}$reduced $\mathrm{MV}^{+}$(Figure S17A). The addition of $\mathrm{NMe}{ }_{4} \mathrm{OH}$ to increase the $\mathrm{TiO}_{2}{ }^{R} \mathrm{pH}$ to 2.75 and subsequent titration with $\mathrm{MV}^{2+}$ gave similar results (Figure S17B). However, the growth of the reduced $\mathrm{MV}^{+}$spectrum as a function of titrated $\left[\mathrm{MV}^{2+}\right]$ is higher in the more basic colloid. This is seen clearly by the steeper slope of $\mathrm{A}_{600 \mathrm{~nm}}$ as a function of $\left[\mathrm{MV}^{2+}\right]$ in the $2.75 \mathrm{pH}$ vs $2.25 \mathrm{pH}$ titrations in Figure S17C. Based on the growth in $\mathrm{MV}^{+}$absorbance relative to the titrated $\mathrm{MV}^{2+}, 18 \%$ of $\mathrm{MV}^{2+}$ is reduced by at $\mathrm{pH} 2.25$ and $51 \%$ of $\mathrm{MV}^{2+}$ is reduced at $\mathrm{pH} 2.75$. According to eq $\mathrm{S} 4.8$, this suggests a $36 \mathrm{mV}$ difference in the reduction potential of the two $\mathrm{TiO}_{2}{ }^{R}$ acidic colloids.

Another aliquot of the uncapped $\mathrm{TiO}_{2}{ }^{R}$ colloid was treated with more base to increase the $\mathrm{pH}$ to 11.7 and then titrated with $\mathrm{MV}^{2+}$. Like in the citrate capped experiments (Figure S15), complete conversion of the titrated $\mathrm{MV}^{2+}$ to $\mathrm{MV}^{0}$ is observed (Figure S18). The lack of any $\mathrm{MV}^{+}$absorbance until the endpoint of the titration (until complete oxidation of $\mathrm{TiO}_{2}^{R}$ ) again suggests that the reducing potential of $\mathrm{TiO}_{2}{ }^{R}$ at $\mathrm{pH}$ 11.7 is much more negative than the $E^{\circ}\left(\mathrm{MV}^{+} / \mathrm{MV}^{0}\right)$. Again, taking the upper limit of possible $\mathrm{MV}^{+}$at any point in the titration to be $<1 \%$ of the total added $\mathrm{MV}^{2+}$, the lower limit of the $u c-\mathrm{TiO}_{2}{ }^{R}$ reduction potential at $\mathrm{pH} 11.7$ is $E_{\mathrm{pH} 11.7}\left(\mathrm{TiO}_{2}{ }^{\mathrm{O} x / R}\right) \leq-0.99 \mathrm{~V}$ vs NHE. 

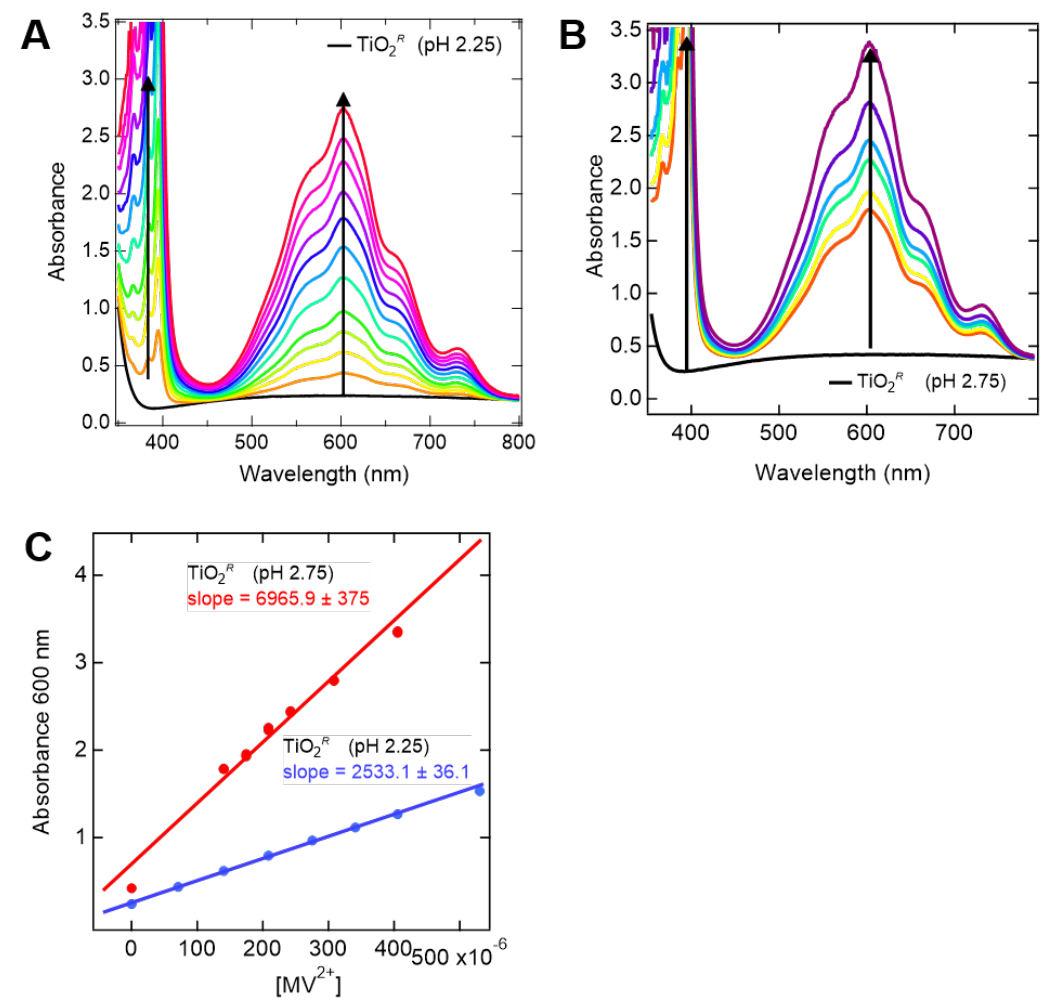

Figure S17: Optical spectra following the titration of $u c-\mathrm{TiO}_{2}{ }^{R}\left(0.9 \mathrm{mM} \mathrm{e}^{-}, \sim 30 \mu \mathrm{M} \mathrm{NPs}, 0.1 \mathrm{mM} \mathrm{MeOH}\right)$ by $\mathrm{MV}^{2+}$ at $(\mathbf{A}) \mathrm{pH} 2.25$ and (B) $\mathrm{pH}$ 2.75. The black arrows track the growth of the $\mathrm{MV}^{+}$peaks at 606 and 395 $\mathrm{nm}$. (C) Absorbance at $600 \mathrm{~nm}$ as a function of $\mathrm{MV}^{2+}$ concentration for the $\mathrm{pH} 2.25$ (blue) and 2.75 (red) titrations.
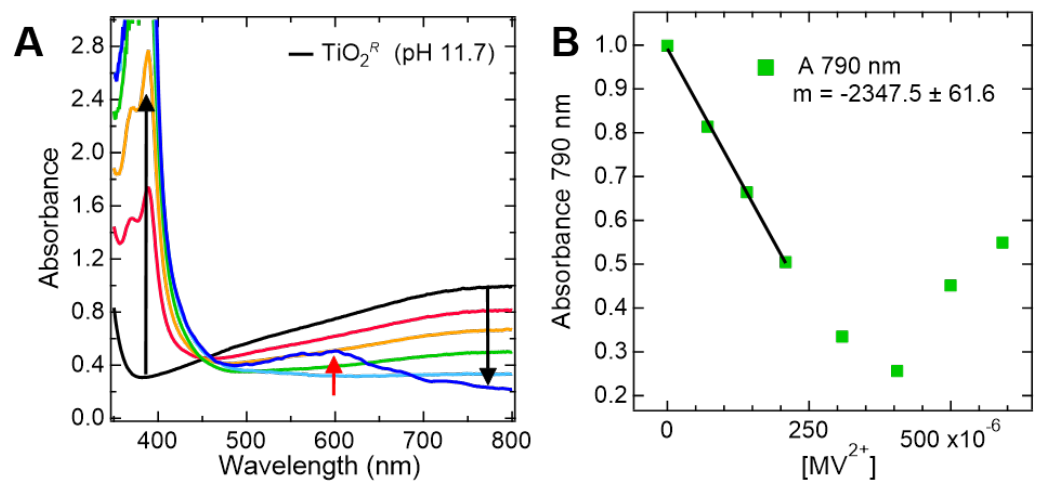

Figure S18: (A) Optical spectra following the titration of $u c-\mathrm{TiO}_{2}{ }^{R}\left(0.7 \mathrm{mM} \mathrm{e}^{-}, \sim 30 \mu \mathrm{M} \mathrm{NPs}, 0.1 \mathrm{mM} \mathrm{MeOH}\right)$ by $\mathrm{MV}^{2+}$ at $\mathrm{pH} 11.70$. The black arrows track the growth of the $\mathrm{MV}^{0}$ at $\mathrm{A}<450 \mathrm{~nm}$ and the disappearance of the broad $\mathrm{TiO}_{2}{ }^{R}$ absorbance feature at $790 \mathrm{~nm}$. The red arrow shows the growth of $\mathrm{MV}^{+}$resulting from the comproportionation of $\mathrm{MV}^{0}$ and $\mathrm{MV}^{2+}$. (B) Absorbance at $790 \mathrm{~nm}$ as a function of $\mathrm{MV}^{2+}$ concentration. 


\section{S4.2 Cobaltocenium-1,1'-dicarboxylate (Co ${ }^{\text {III }}$ )}

In accordance with the previous studies of Kölle and Grätzel, $\left[\mathrm{Co}^{3+}\left(\mathrm{cp}-\mathrm{COO}^{-}\right)_{2}\right]^{+}$, abbreviated Co'II, was synthesized and used to probe the $E\left(\mathrm{TiO}_{2}{ }^{\mathrm{Ox} / R}\right)$ of $\mathrm{C}-\mathrm{TiO}_{2}{ }^{R}$ at near neutral $\mathrm{pH}^{32}$ Because the carboxylate functionalities of the reduced complex, Co(II), are more basic than those of the oxidized complex (pKa(2+) $>$ $\left.\mathrm{p} K_{\mathrm{a}(3+)}\right)$, ET to $\mathrm{Co}(\mathrm{III})$ is coupled to the transfer of $2 \mathrm{H}^{+}$when $2.9<\mathrm{pH}<5.8$ (Scheme S5). The difference in the reduction potential $\left(E^{\circ}-E^{\circ}\right)$ over the difference in the $\mathrm{p} K_{\mathrm{a}}$ values $\left(\mathrm{p} K_{\mathrm{a}(2+)}-\mathrm{p} K_{\mathrm{a}(3+)}\right)$ gives $100 \mathrm{mV}$ per $\mathrm{pH}$ unit, which is close to the predicted $120 \mathrm{mV}$ for a $1 e^{-}: 2 \mathrm{H}^{+}$processes.

Scheme S5: Thermochemical square scheme showing the addition of $2 \mathrm{H}^{+}$(horizontal arrows), $1 \mathrm{e}^{-}$(vertical arrows) or $2 \mathrm{H}^{+}$and $1 \mathrm{e}^{-}$(2-proton-coupled ET, diagonal arrow), to a $\mathrm{Co}^{3+}\left(\mathrm{cp}-\mathrm{COO}^{-}\right) 2 .{ }^{32} \mathrm{Note}$, as reported by Kölle and Grätzel the $\mathrm{pK}$ a values of both carboxylates are equal in the Co(II) and Co(III) complexes. Reported $E^{\circ}$ are vs. NHE.

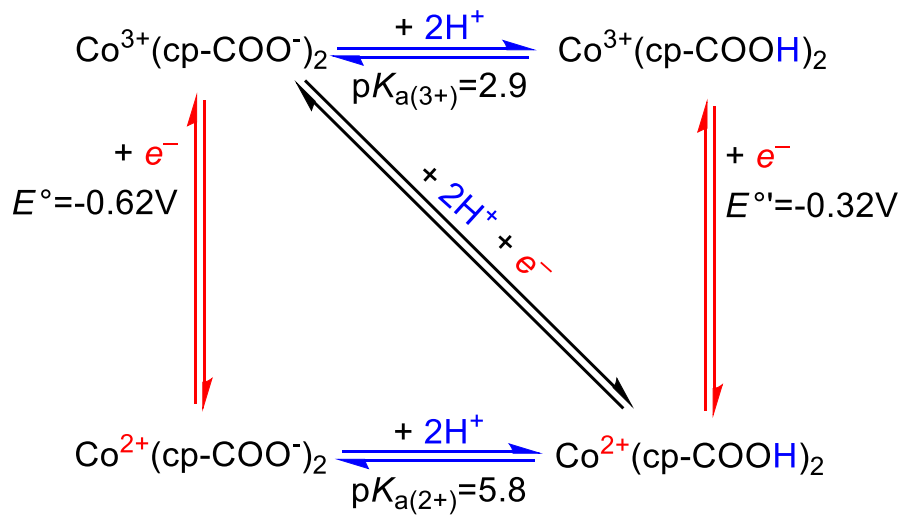

Table S4: The epsilons of protonated and deprotonated Co(II/III) complexes. ${ }^{32}$ Kölle reported an epsilon of $\varepsilon_{484 \mathrm{~nm}}$ of $1,600 \mathrm{M}^{-1} \mathrm{~cm}^{-1}$ for $\mathrm{Co}^{2+}\left(\mathrm{cp}-\mathrm{COO}^{-}\right)_{2}$; however, our measurements indicated that the epsilon was larger, $\varepsilon_{484 \mathrm{~nm}}=2,000 \pm 100 \mathrm{M}^{-1} \mathrm{~cm}^{-1}$. ${ }^{*}$ Our larger epsilon was used in the analysis of the $\mathrm{Co}^{\text {IIII }}$ titrations of $\mathrm{TiO}_{2}{ }^{R}$.

\begin{tabular}{|c|c|c|c|}
\hline & $\begin{array}{c}\mathrm{Co}^{3+}\left(\mathrm{cp}-\mathrm{COO}^{-}\right)_{2} \text { and } \\
\mathrm{Co}^{3+}(\mathrm{cp}-\mathrm{COOH})_{2}\end{array}$ & $\mathrm{Co}^{2+}\left(\mathrm{cp}-\mathrm{COO}^{-}\right)_{2}$ & $\mathrm{Co}^{2+}(\mathrm{cp}-\mathrm{COOH})_{2}$ \\
\hline$\varepsilon\left(\mathrm{M}^{-1} \mathrm{~cm}^{-1}\right)$ & $410 \mathrm{~nm}, \varepsilon=240$ & $\begin{array}{c}484 \mathbf{n m}^{32}, \varepsilon=1,600 \\
* 484 \mathrm{~nm}, \varepsilon=2,000 \pm 100\end{array}$ & $\begin{array}{c}516 \mathbf{n m}, \varepsilon=1,700 \\
454 \mathrm{~nm}, \varepsilon=1,600\end{array}$ \\
\hline
\end{tabular}

The epsilons of the Coll and Co'll complexes are listed in Table S4. Because the epsilons of the Co are only $\sim 1$ order of magnitude larger than those of $c-\mathrm{TiO}_{2}{ }^{\mathrm{R}}$, eq $\mathrm{S} 4.2$ through eq $\mathrm{S} 4.4$ were used in the analysis of the $\mathrm{Co}^{\text {III }}$ titrations in order to account for the $\triangle \mathrm{A}$ from both $c-\mathrm{TiO}_{2}$ and $\mathrm{Co}(\mathrm{III} / \mathrm{II})$.

At $\mathrm{pH}>9.2$, the titration of $c-\mathrm{TiO}_{2}{ }^{R}\left(\mathrm{pH} 12.6,1.1 \mathrm{mM} \mathrm{e} e^{-}, \sim 30 \mu \mathrm{M} \mathrm{NPs}, 4.2 \mathrm{mM}\right.$ citric acid) by Co $0^{\prime \prime \prime}$ results in the linear decrease in the broad $\mathrm{TiO}_{2}{ }^{R}$ optical peak and the growth of a new peak at $488 \mathrm{~nm}$ (Figure $\mathrm{S} 19 \mathrm{~A}$ ). The $\triangle \mathrm{A} \times \mathrm{Vol}$ at $800 \mathrm{~nm}$ as a function of mol Coll' is $-1260 \mathrm{M}^{-1} \mathrm{~cm}^{-1}$ (Figure S19B), equal to the epsilon of reduced $\mathrm{TiO}_{2}$ at $\mathrm{pH} 12, \varepsilon 790 \mathrm{~nm}=1,400 \pm 150 \mathrm{M}^{-1} \mathrm{~cm}^{-1}$. The absorbance change at $484 \mathrm{~nm}$ results from the increase in $\mathrm{Co}$ "l absorbance and the decrease in the $c-\mathrm{TiO}_{2}{ }^{R}$ absorbance. The $\varepsilon$ of $\mathrm{Co}^{\text {Il }}$ was calculated from 
eq S4.11, where $\delta$ is approximated to be 1 , indicating roughly $100 \%$ reduction of $\mathrm{Co}(\mathrm{III})$ to $\mathrm{Co}(\mathrm{II})$, and the $\varepsilon \mathrm{TTO}_{\mathrm{T} R}\left(=595 \mathrm{M}^{-1} \mathrm{~cm}^{-1}\right)$ was calculated from the total absorbance change and the known $\left[c-\mathrm{TiO}_{2}{ }^{R}\right]$ init.

eq S4.11 $\quad A \times V_{\text {ollot }}=\mathrm{Co}(\mathrm{III}) \mathrm{mol} \times+\delta\left(\varepsilon \mathrm{Co}(\mathrm{II})-\varepsilon_{\mathrm{TiO} 2 R}\right)$

Similar to the high $\mathrm{pH}$ titrations of $c-\mathrm{TiO}_{2}{ }^{R}$ with $\mathrm{MV}^{2+}$, these results are consistent with the quantitative reduction of $\mathrm{Co}^{\mathrm{III}}$ by $\mathrm{TiO}_{2}{ }^{R}$. Based on this result, \%Co(II) (Red) was approximated to be $99 \%$, and eq $\mathrm{S} 4.8$ was used to determine a lower limit for $E\left(\mathrm{TiO}_{2}{ }^{\mathrm{O} / R}\right)$ at $\mathrm{pH} 9.2 ; E_{\mathrm{pH} 9.2}\left(\mathrm{TiO}_{2}{ }^{\mathrm{O} / R}\right) \approx-0.74 \mathrm{~V}$ vs NHE.

A

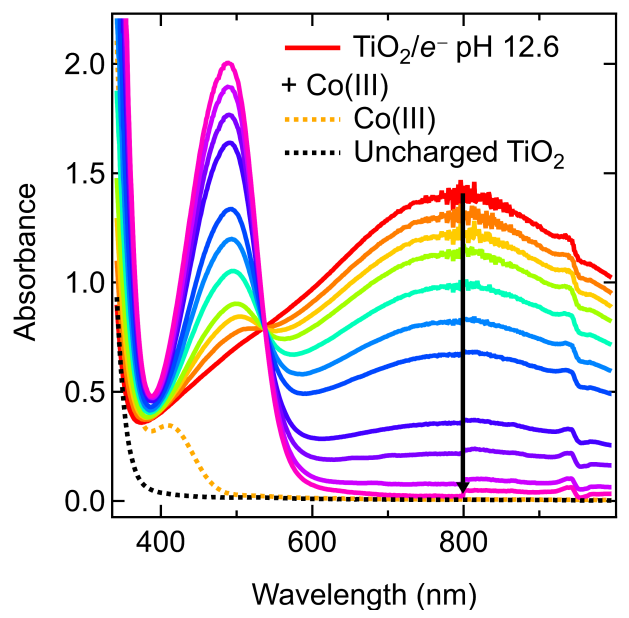

B

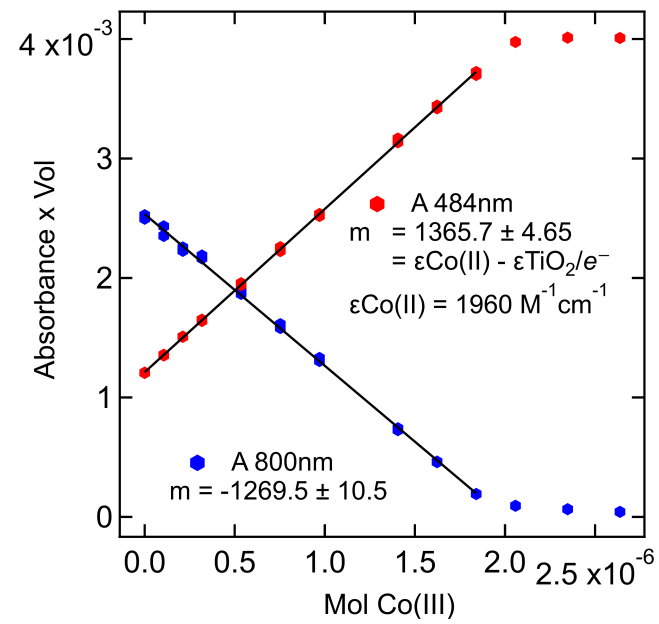

Figure S19: (A) Optical spectra following the titration of $c-\mathrm{TiO}_{2}{ }^{R}(\mathrm{pH} 12.6,1.1 \mathrm{mM} \mathrm{e}, \sim 20 \mu \mathrm{M} \mathrm{NPs}, 4.2 \mathrm{mM}$ citric acid) by $\mathrm{Co}^{\prime \prime \prime}$, black arrow. The spectrum of uncharged $c-\mathrm{TiO}_{2}$ and $\mathrm{Co}(\mathrm{III})$ have been included, dashed traces. (B) A plot of absorbance $\times$ volume vs. mol Co'"!.

Under more acidic conditions, $\mathrm{pH} \leq 4.7$, the addition of $\mathrm{Co}^{\prime \prime \prime}$ to $c-\mathrm{TiO}_{2}{ }^{R}$ results in almost no change in the optical spectrum, aside from the growth of the Co'l' peak, Figure S20. Only a very small peak at 516 $\mathrm{nm}$, corresponding to $\sim 1 \%$ reduction of $\mathrm{Co}$ (III) to protonated $\mathrm{Co}(\mathrm{II})$ is observed under these conditions. The $2 \mathrm{H}^{+}$-coupled $\mathrm{Co}(\mathrm{III})$ reduction potential, $\mathrm{E}_{\mathrm{pH} 4.7}^{\circ}\left(\mathrm{Co}(\mathrm{III}) / \mathrm{Co}(\mathrm{II}) \mathrm{H}^{+}{ }_{2}\right)$, was estimated to be $-0.59 \mathrm{~V}$ verse $\mathrm{NHE} .{ }^{32}$ Thus, $E\left(\mathrm{TiO}_{2}{ }^{\mathrm{O} x / R}\right)$ at $\mathrm{pH} 4.7$ was calculated to be $-0.47 \mathrm{~V}$ verse $\mathrm{NHE}$. 


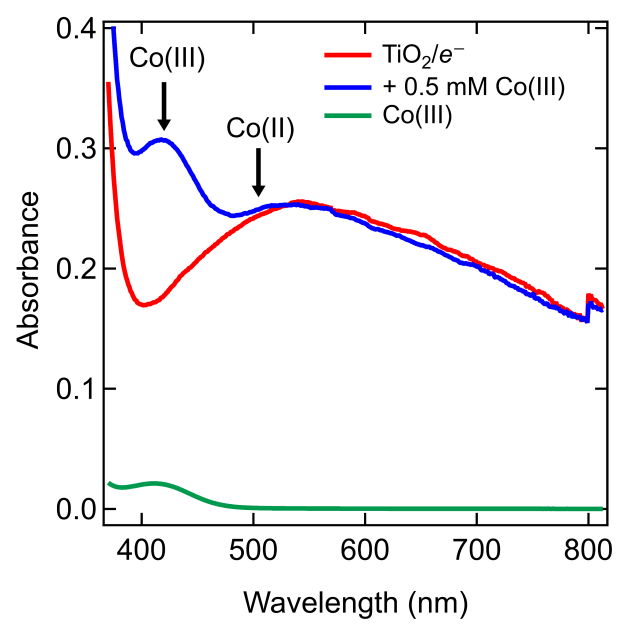

Figure S20: Optical spectra before and after the addition of $\mathrm{Co}(\mathrm{III})(0.5 \mathrm{mM})$ to $c-\mathrm{TiO}_{2}{ }^{R}\left(\mathrm{pH} 4.7,1.5 \mathrm{mM} e^{-}\right.$ , $\sim 30 \mu \mathrm{M}$ NPs, $4.2 \mathrm{mM}$ citric acid). A spectrum of Coll' has been included for reference (green trace). The very small peak at $516 \mathrm{~nm}$ is consistent with the formation of $\sim 1 \% \mathrm{Co}^{2+}(\mathrm{cp}-\mathrm{COOH})_{2}$, see Table S4.

A

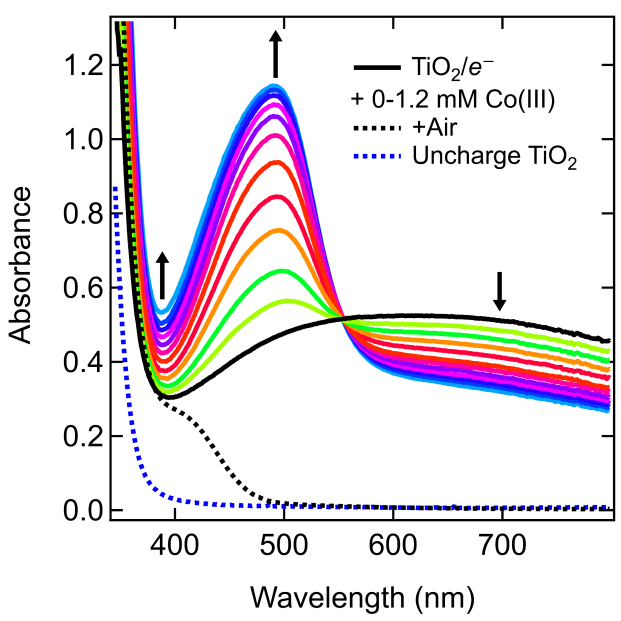

B

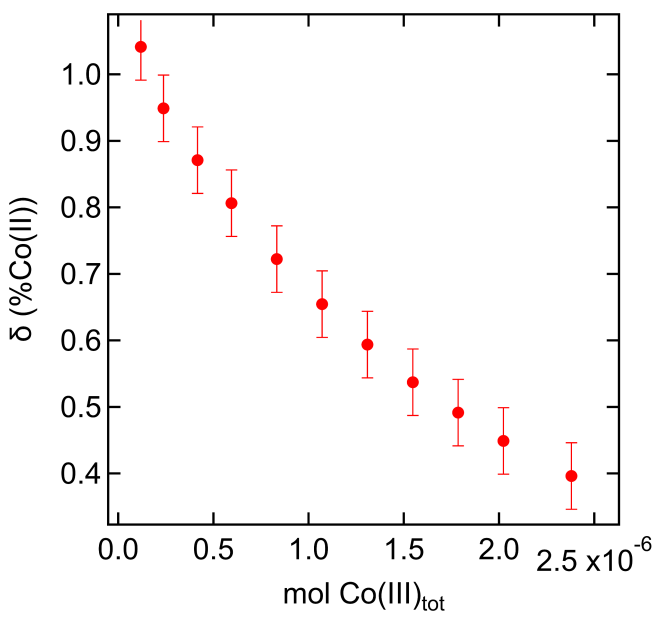

Figure S21: (A) Optical spectra following the titration of $\mathrm{TiO}_{2}{ }^{R}\left(\mathrm{pH} 6.4,1.8 \mathrm{mM} e^{-}, \sim 30 \mu \mathrm{M} N \mathrm{Ns}, 5.5 \mathrm{mM}\right.$ citric acid) by $\mathrm{Co}(\mathrm{III})$, black arrow. The spectrum of uncharged $\mathrm{TiO}_{2}$ and the titrated solution +air have been included, dashed traces. (B) A plot of $\delta(\% \mathrm{Co}(\mathrm{II}))$ vs. titrated mol Co(III). $\delta$ was determined at each point of the titration using eq S4.12 and absorbance and epsilons at $484 \mathrm{~nm}$.

At near neutral $\mathrm{pH}$ (6-8.5), titration of $c-\mathrm{TiO}_{2}{ }^{R}$ with $\mathrm{Co}$ "ll are complicated due to the slight acidification of the colloid upon oxidation with $\mathrm{Co}^{\prime \prime \prime}$. Like the $\mathrm{Kl}_{3}$ oxidant discussed in the main text of this chapter, at $\mathrm{pH}>$ $5.8\left(\mathrm{p} K_{\mathrm{a}(2+)}\right), \mathrm{Co}(\mathrm{III})$ is an electron only oxidant. Upon reduction of $\mathrm{Co}^{\prime \prime \prime}$, above $\mathrm{pH} 5.8$, by $\mathrm{c}-\mathrm{TiO}_{2}{ }^{R}$, the protons coupled to the additional electron in $\mathrm{TiO}_{2}{ }^{R}$ are transferred to the colloid resulting in the acidification of the colloid by $\sim 0.5-1.0 \mathrm{pH}$ units. As a result of the colloid acidification (within this relatively unbuffered $\mathrm{pH}$ range), both the epsilon and the reduction potential, $E\left(\mathrm{TiO}_{2}{ }^{\mathrm{O} / R}\right)$, of the reduced NPs shift; the epsilon decreases by roughly $100 \mathrm{M}^{-1} \mathrm{~cm}^{-1}$ per $\mathrm{pH}$ unit (Figure S21B) and the $E\left(\mathrm{TiO}_{2}{ }^{\mathrm{O} / R}\right)$ is predicted to become more positive by roughly $60 \mathrm{mV}$ per $\mathrm{pH}$ unit. 
The titration of $\mathrm{TiO}_{2}{ }^{R}\left(\mathrm{pH} 6.4,1.8 \mathrm{mM} \mathrm{e}^{-}, \sim 30 \mu \mathrm{M} \mathrm{NPs}, 5.5 \mathrm{mM}\right.$ citric acid) by Co(III) is shown in Figure S21A. Using eq S4.13 and the known epsilon and measured absorbance at $A_{484 n m}, \delta$, representing the fraction of reduction $\mathrm{Co}(\mathrm{II})$, was determined at each point in the titration (Figure S21B). As the titration progresses, less and less of the added $\mathrm{Co}(\mathrm{III})$ is reduced to $\mathrm{Co}(\mathrm{II})$. The buildup of [Co(III)] is indicated by the growth of $A_{410 n m}$ in the optical data (Figure S21A). Due to the complexities of these titrations, only the final $\% \mathrm{Co}(\mathrm{II})$ and the (air oxidized) $\mathrm{pH}$ from these titrations were used to evaluate $E\left(\mathrm{TiO}_{2}{ }^{\mathrm{O} / R}\right)$.

\section{S4.3 Eu(III)DPTA}

$\mathrm{K}_{2}\left[\mathrm{Eu}(\mathrm{III}) \mathrm{DTPA}\left(\mathrm{H}_{2} \mathrm{O}\right)\right](\mathrm{DTPA}=$ diethylenetriamine pentaacetate $)$ was prepared following the procedure of Liu et al. ${ }^{38}$ The optical spectra of the prepared material were consistent with the literature values (Figure $\mathrm{S} 22)$. The low reduction potential of $\mathrm{Eu}(\mathrm{III}) \mathrm{DTPA}\left(E^{\circ}(\mathrm{Eu}(\mathrm{III} / \mathrm{II}) \mathrm{DTPA})=-1.14 \mathrm{~V}\right.$ vs $\left.\mathrm{NHE}\right)$ is ideal for probing the $E\left(\mathrm{TiO}_{2}{ }^{\mathrm{O} x / R}\right)$ of highly reducing, high $\mathrm{pH} \mathrm{TiO}_{2}{ }^{R} \cdot{ }^{39,40}$ However, the $\mathrm{Eu}(\mathrm{III} / \mathrm{II}) \mathrm{DTPA}$ complexes, which absorb primarily below the conduction band of $\mathrm{TiO}_{2}$, do not provide any optical handle for analyzing the optical titration data. ${ }^{39}$ Thus, the change in $\mathrm{TiO}_{2}{ }^{R}$ absorbance was used to analyze the reactions of $\mathrm{TiO}_{2}{ }^{R}$ with Eu(III)DPTA.

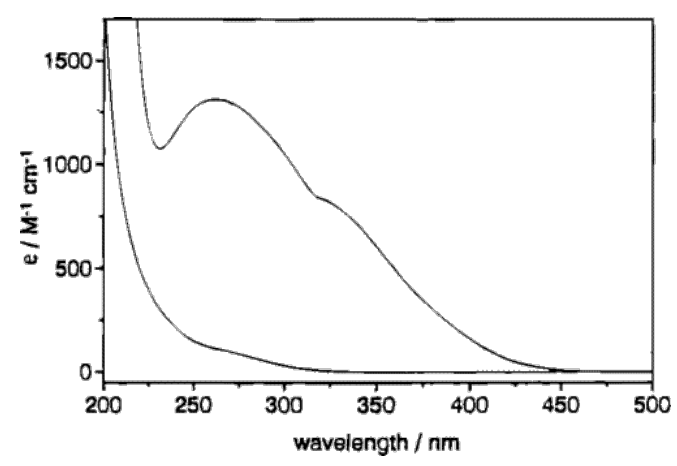

Figure S22: Molar absorptivity $(\varepsilon)$ of $\operatorname{Eu}(\mathrm{III}) \mathrm{DTPA}\left(\varepsilon_{275 \mathrm{~nm}}=100 \mathrm{M}^{-1} \mathrm{~cm}^{-1}\right)$ and $\mathrm{Eu}(\mathrm{II})\left(\varepsilon_{257 \mathrm{~nm}}=1,300 \mathrm{M}^{-1} \mathrm{~cm}^{-1}\right.$, $\varepsilon_{320 \mathrm{~nm}}=850 \mathrm{M}^{-1} \mathrm{~cm}^{-1}$ ) plotted vs. wavelength. ${ }^{39}$ Reproduced from Seibig, S.; Tóth, É.; Merbach, A. E., J. Am. Chem. Soc. 2000, 122, 5822. Copyright 2000 American Chemical Society.

The addition of $\sim 6$ equivalents Eu(III)DPTA (4.3 mM) to pH $12.7 c-\mathrm{TiO}_{2}{ }^{R}\left(0.7 \mathrm{mM} \mathrm{e} e^{-}, \sim 20 \mu \mathrm{M} \mathrm{NPs}, 4.2\right.$ $\mathrm{mM}$ citric acid) resulted in the slow decrease in the broad $c-\mathrm{TiO}_{2}{ }^{\mathrm{R}}$ peak (Figure S23A). Because the $c-\mathrm{TiO}_{2}{ }^{R}$ absorbance decay was observed over several hours, the absorbance of $\mathrm{TiO}_{2}{ }^{R}$ (without added oxidant) was followed as a control. A $59 \%$ decrease in the $\mathrm{TiO}_{2}{ }^{R}$ absorbance was observed two hours after the addition of Eu(III)DTPA, and a $92 \%$ decrease was observed at 16 hours. Additionally, the absorbance near the $\mathrm{TiO}_{2}$ band edge increased slightly on this timescale (Figure S23A, up arrow). A less significant decay in the control $\mathrm{TiO}_{2}{ }^{R}$ spectrum was also observed on the 16 -hour timescale, $0 \%$ at $2 \mathrm{~h}$ and $19 \%$ at $16 \mathrm{~h}$ (Figure S23A, dashed traces).

The decrease in the $\mathrm{TiO}_{2}{ }^{R}$ optical signal and the parallel increase in absorbance near the $\mathrm{TiO}_{2}$ band edge are respectively consistent with the oxidation of $\mathrm{TiO}_{2}{ }^{R}$ and the formation of Eu(II)DTPA (Figure S22). However, the control experiment suggests that at least $\sim 20 \%$ of the decay in the $\mathrm{TiO}_{2}{ }^{R}+\mathrm{Eu}(\mathrm{III}) \mathrm{DTPA}$ 
spectrum results from side reactions unrelated the Eu(III)DTPA. Still, these initial results suggest that $\sim 70 \%$ of the $\mathrm{TiO}_{2}{ }^{R}$ is oxidized by Eu(III)DTPA, which gives $11 \%$ reduction of Eu(III)DPTA to Eu(II).

A

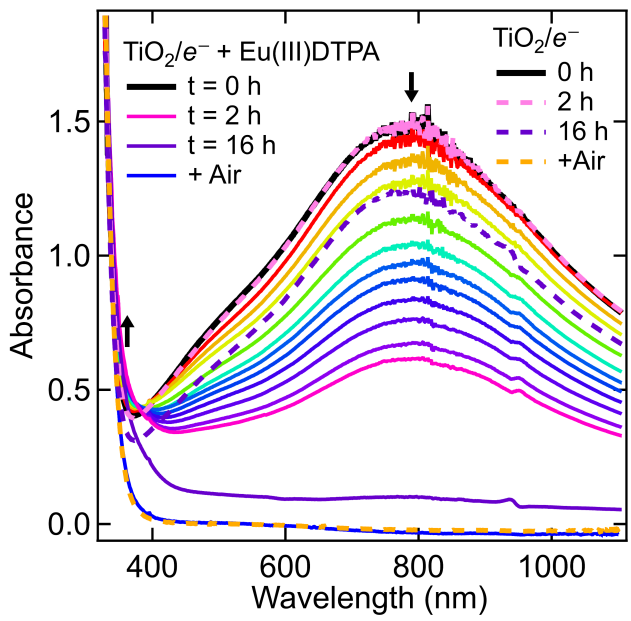

B

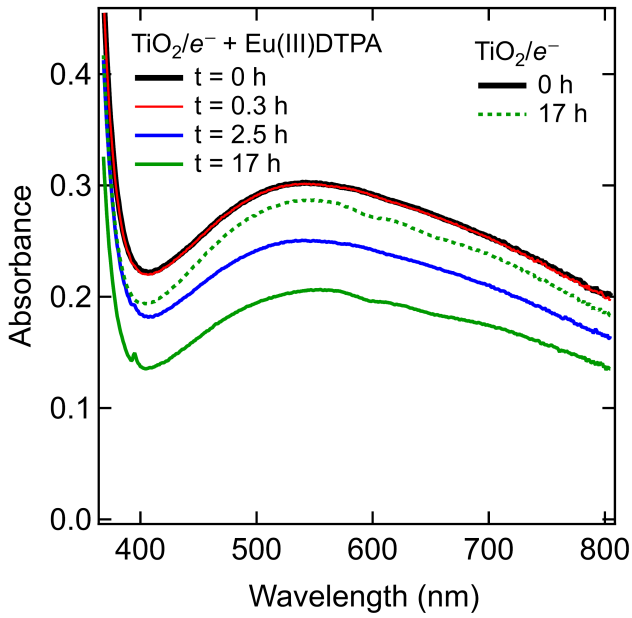

Figure S23: (A) Optical spectra of pH $12.7 c-\mathrm{TiO}_{2}{ }^{R}(0.7 \mathrm{mM} \mathrm{e}, \sim 20 \mu \mathrm{M}$ NPs, $4.2 \mathrm{mM}$ citric acid) with (solid) and without (dashed) the addition of 6 equivalents Eu(III)DTPA ( $4.3 \mathrm{mM})$. The optical spectrum of the colloid

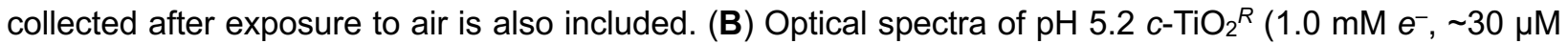
$\mathrm{NPs}, 6 \mathrm{mM}$ citric acid) with (solid) and without (dashed) the addition of Eu(III)DTPA (4.3 mM).

The reaction of $c-\mathrm{TiO}_{2}{ }^{R}$ and $\mathrm{Eu}(\mathrm{III}) \mathrm{DTPA}$ was also followed at pH 5.2 over the course of 17 hours (Figure $\mathrm{S} 23 \mathrm{~B})$. Surprisingly, the optical spectrum of $\mathrm{TiO}_{2}{ }^{R}+\mathrm{Eu}(\mathrm{III}) \mathrm{DPTA}$ decayed more ( $33 \%$ at $17 \mathrm{~h}$, solid traces) than the stock $\mathrm{TiO}_{2}{ }^{R}$ sample $(7 \%$ at $17 \mathrm{~h}$, dashed traces), Figure S23B. However, no increase in the absorbance near to the $\mathrm{TiO}_{2}$ band edge was observed.

This result seems to indicate that Eu(III)DTPA is reduced by the pH $5.2 c-\mathrm{TiO}_{2}{ }^{R}$. However, unlike the high $\mathrm{pH}$ reaction, the absorbance near to the $\mathrm{TiO}_{2}$ band edge does not increase at $\mathrm{pH} 5.2$, i.e., the formation of Eu(II)DPTA is not indicated in this experiment. Seibig et al. reported the dissociation of the Eupolyaminocarboxylate complex below $\mathrm{pH} 7$ to form Eu aquo species $\left(\mathrm{Eu}(\mathrm{III})_{\mathrm{aq}}\right)$. $\mathrm{Eu}(\mathrm{III})_{\text {aq }}$ is a much stronger oxidant that Eu(III)DTPA and has a reduction potential similar to the $\mathrm{MV}^{2+} / \mathrm{MV}^{+}$couple (Table S3), Eu(III/II)aq $=-0.40 \mathrm{~V}$ (Table S5). ${ }^{39}$ Under the conditions studied here, the additional oxidation of the $c-\mathrm{TiO}_{2}{ }^{R}$ colloid treated with $\mathrm{Eu}(\mathrm{III}) \mathrm{DTPA}$ likely results from the formation and reduction of the $\mathrm{Eu}(\mathrm{III})$ aquo complex.

Table S5: The redox potentials of Eu(III/II)DTPA and Eu(III/II) aq complexes. ${ }^{39,40}$ Reported $E^{\circ}$ are vs. NHE.

\begin{tabular}{|l|c|l|}
\hline & Eu(III/II)DPTA & Eu(III/II) $)_{\mathrm{aq}}$ \\
\hline$E^{\circ}$ vs NHE & $-1.14 \mathrm{~V}$ & $-0.40 \mathrm{~V}$ \\
\hline
\end{tabular}




\section{S4.4 Compiled Titration Data}

The oxidant $(\mathrm{Ox}), \mathrm{pH},\left[\mathrm{e}^{-}\right]$, [citric acid], calculated $E(\mathrm{Ox} / \mathrm{Red})$, and experiment date of each titration plotted in Manuscript Figure 4 is listed in Table S6. Properties of the oxidants are given in Table S7.

Table S6: The Oxidant (Ox), $\mathrm{pH},\left[e^{-}\right]$, [citric acid], calculated $E(\mathrm{Ox} / \mathrm{Red})$, and experiment date of each titration plotted in Manuscript Figure 4. The pH was measured on the bench top after exposure of the titrated sample to air. Citric acid concentration refers to the pre-photolysis concentration.

\begin{tabular}{|c|c|c|c|c|}
\hline $\mathbf{O x}$ & $\mathbf{p H}$ & {$\left[e^{-}\right]$} & [Citric Acid] & $E($ Ox/Red) V vs NHE \\
\hline $\mathbf{M V}^{2+}$ & 3.8 & 1.65 & 18.46 & -0.402 \\
\hline $\mathbf{M V}^{2+}$ & 4.8 & 1 & 17.9 & -0.408 \\
\hline $\mathbf{M V}^{2+}$ & 3.3 & 0.99 & 17 & -0.348 \\
\hline $\mathrm{MV}^{2+}$ & 5.5 & 1 & 5.9 & -0.47 \\
\hline $\mathrm{MV}^{2+}$ & 5.2 & 1 & 5.7 & -0.469 \\
\hline $\mathrm{MV}^{2+}$ & 5.1 & 1 & 5.7 & -0.458 \\
\hline $\mathbf{M V}^{2+}$ & 2.8 & 1 & 5.7 & -0.382 \\
\hline $\mathrm{MV}^{2+}$ & 5.6 & 0.34 & 5.4 & -0.433 \\
\hline $\mathrm{MV}^{2+}$ & 5.7 & 0.5 & 9.4 & -0.502 \\
\hline $\mathbf{M V}^{2+}$ & 5.7 & 0.42 & 5.8 & -0.443 \\
\hline $\mathbf{M V}^{+}$ & 12.8 & 0.9 & 14.38 & -0.998 \\
\hline Co(III) & 4.7 & 1.5 & 5.65 & -0.472 \\
\hline $\mathrm{Co}(\mathrm{III})$ & 7.6 & 1.4 & 5.5 & -0.62 \\
\hline Co(III) & 9.2 & 1.34 & 5.5 & -0.738 \\
\hline $\mathrm{Co}(\mathrm{III})$ & 6.4 & 1.8 & 5.7 & -0.609 \\
\hline $\mathrm{Co}(\mathrm{III})$ & 7.14 & 1.3 & 5.7 & -0.614 \\
\hline $\mathrm{Co}(\| I I)$ & 5.06 & 1.3 & 5.7 & -0.482 \\
\hline $\mathrm{Co}(I I I)$ & 8.23 & 1.3 & 5.7 & -0.644 \\
\hline Eu(III)EDTA & 12.7 & 0.7 & 3.9 & -1.087 \\
\hline
\end{tabular}


Table S7: Data for Ox/Red couples used to probe the $\mathrm{TiO}_{2}$ potential as a function of $\mathrm{pH}$, including the applicable $\mathrm{pH}$ range. ${ }^{a}$

\begin{tabular}{|c|c|c|c|c|}
\hline Ox/Red ${ }^{a}$ & $\begin{array}{l}\lambda_{\max } \\
(\mathrm{nm})\end{array}$ & $\begin{array}{c}\varepsilon \\
\left.\mathbf{M}^{-1} \mathbf{c m}^{-1}\right)\end{array}$ & $E^{\circ}(O x /$ Red $)$ & $\mathrm{pH}$ \\
\hline $\mathbf{M V}^{2+} / \mathbf{M V}^{+}$ & $\begin{array}{l}395 \\
606\end{array}$ & $\begin{array}{l}42,100 \\
13,700\end{array}$ & $-0.446 \mathrm{~V}$ & $2-6$ \\
\hline $\begin{array}{l}\mathrm{Co}^{\prime \prime \prime} / \mathrm{Co}^{\prime \prime} \mathrm{H}_{2} \\
\mathrm{CO}_{2}(\mathrm{H}) \\
\mathrm{CoO}_{2}(\mathrm{H})\end{array}$ & $\begin{array}{l}516 \\
454\end{array}$ & $\begin{array}{l}1,700 \\
1,600\end{array}$ & $-0.32 \mathrm{~V}^{b}$ & $4-5.8$ \\
\hline $\begin{array}{l}\mathrm{Co}^{\prime \prime \prime} / \mathrm{Co}^{\prime \prime \prime} \\
\mathrm{Co}^{\prime \prime 1 / 1 / 1} \mathrm{CO}_{2}^{-} \\
\mathrm{CO}_{2}^{-}\end{array}$ & 484 & 2,000 & $-0.62 \mathrm{~V}$ & $5.8-9.5$ \\
\hline $\mathbf{M V}^{+} / \mathbf{M V}^{\mathbf{0}}$ & 385 & 46,000 & $-0.88 \mathrm{~V}$ & $>10$ \\
\hline $\begin{array}{c}\text { Eu"'DTPA/ } \\
\text { Eu"DTPA }\end{array}$ & $\begin{array}{l}257 \\
320\end{array}$ & $\begin{array}{c}1,300 \\
850\end{array}$ & $-1.14 \mathrm{~V}$ & $>10$ \\
\hline
\end{tabular}

${ }^{a} \mathrm{MV}^{\mathrm{n}}=$ methylviologen ${ }^{2++/ 0} ; \mathrm{Co}^{\mathrm{III}}=$ cobaltocenium-1,1'-dicarboxylate; and Eu'IIDTPA = Europium(III) diethylenetriamine pentaacetate ${ }^{b} \mathrm{Co}^{\mathrm{II \prime} /} / \mathrm{Co}^{\prime \prime} \mathrm{H}_{2}$ is a $2 e^{-} / 2 \mathrm{H}^{+} \mathrm{PCET}$ half reaction below $\mathrm{pH} 5.8$, so the $E$ shifts as a function of $\mathrm{pH}$. 


\section{S5 References for Supporting Information}

1. Peper, J. L.; Vinyard, D. J.; Brudvig, G. W.; Mayer, J. M., Slow Equilibration between Spectroscopically Distinct Trap States in Reduced $\mathrm{TiO}_{2}$ Nanoparticles. J. Am. Chem. Soc. 2017, 139, 2868-2871.

2. Peper, J. L.; Gentry, N. E.; Brezny, A. C.; Field, M. J.; Green, M. T.; Mayer, J. M., Different Kinetic Reactivities of Electrons in Distinct $\mathrm{TiO}_{2}$ Nanoparticle Trap States. J. Phys. Chem. C 2021, 125, 680690.

3. Provencher, S. W., CONTIN: A general purpose constrained regularization program for inverting noisy linear algebraic and integral equations. Comput. Phys. Commun. 1982, 27, 229-242.

4. Provencher, S. W., A constrained regularization method for inverting data represented by linear algebraic or integral equations. Comput. Phys. Commun. 1982, 27, 213-227.

5. Mohamed, H. H.; Mendive, C. B.; Dillert, R.; Bahnemann, D. W., Kinetic and Mechanistic Investigations of Multielectron Transfer Reactions Induced by Stored Electrons in $\mathrm{TiO}_{2}$ Nanoparticles: A Stopped Flow Study. J. Phys. Chem. A 2011, 115, 2139-2147.

6. Hoffmann, M. R.; Martin, S. T.; Choi, W.; Bahnemann, D. W., Environmental Applications of Semiconductor Photocatalysis. Chemical Reviews 1995, 95, 69-96.

7. Kaszuba, M.; Corbett, J.; Watson, F. M.; Jones, A., High-Concentration Zeta Potential Measurements Using Light-Scattering Techniques. Philos. Trans. Royal Soc. A 2010, 368, 4439-4451.

8. Kormann, C.; Bahnemann, D. W.; Hoffmann, M. R., Preparation and characterization of quantum-size titanium dioxide. J. Phys. Chem. 1988, 92, 5196-5201.

9. Fernández-Nieves, A.; Nieves, F. J.; Richter, C., Point of zero charge estimation for a $\mathrm{TiO}_{2} /$ water interface. In Trends in Colloid and Interface Science XII, Koper, G. J. M.; Bedeaux, D.; Cavaco, C.; Sager, W. F. C., Eds. Steinkopff: Darmstadt, 1998; Vol. 110, pp 21-24.

10. Mudunkotuwa, I. A.; Grassian, V. H., Citric Acid Adsorption on $\mathrm{TiO}_{2}$ Nanoparticles in Aqueous Suspensions at Acidic and Circumneutral pH: Surface Coverage, Surface Speciation, and Its Impact on Nanoparticle-Nanoparticle Interactions. J. Am. Chem. Soc. 2010, 132, 14986-14994.

11. Krȩżel, A.; Bal, W., A formula for correlating $p K_{a}$ values determined in $\mathrm{D}_{2} \mathrm{O}$ and $\mathrm{H}_{2} \mathrm{O}$. J. Inorg. Biochem. 2004, 98, 161-166.

12. Covington, A. K.; Paabo, M.; Robinson, R. A.; Bates, R. G., Use of the glass electrode in deuterium oxide and the relation between the standardized $\mathrm{pD}(\mathrm{paD})$ scale and the operational $\mathrm{pH}$ in heavy water. Anal. Chem. 1968, 40, 700-706.

13. Glasoe, P. K.; Long, F. A., Use of Glass Electrodes to Measure Acidities in Deuterium Oxide. J. Phys. Chem. 1960, 64, 188-190.

14. Mikkelsen, K.; Nielsen, S. O., Acidity Measurements with the Glass Electrode in $\mathrm{H}_{2} \mathrm{O}-\mathrm{D}_{2} \mathrm{O}$ Mixtures. J. Phys. Chem. 1960, 64, 632-637.

15. Panayotov, D. A.; Burrows, S. P.; Morris, J. R., Photooxidation Mechanism of Methanol on Rutile $\mathrm{TiO}_{2}$ Nanoparticles. J. Phys. Chem. C 2012, 116, 6623-6635.

16. Augugliaro, V.; Bellardita, M.; Loddo, V.; Palmisano, G.; Palmisano, L.; Yurdakal, S., Overview on Oxidation Mechanisms of Organic Compounds by $\mathrm{TiO}_{2}$ in Heterogeneous Photocatalysis. J. Photochem. Photobiol. C 2012, 13, 224-245.

17. Seraghni, N.; Belattar, S.; Mameri, Y.; Debbache, N.; Sehili, T., Fe(III)-Citrate-Complex-Induced Photooxidation of 3-Methylphenol in Aqueous Solution. Int. J. Photoenergy 2012, 2012, e630425.

18. Leytner, S.; Hupp, J. T., Evaluation of the energetics of electron trap states at the nanocrystalline titanium dioxide/aqueous solution interface via time-resolved photoacoustic spectroscopy. Chem. Phys. Lett. 2000, 330, 231-236.

19. Ji, Y.; Wang, B.; Luo, Y., A Comparative Theoretical Study of Proton-Coupled Hole Transfer for $\mathrm{H}_{2} \mathrm{O}$ and Small Organic Molecules $\left(\mathrm{CH}_{3} \mathrm{OH}, \mathrm{HCOOH}, \mathrm{H}_{2} \mathrm{CO}\right)$ on the Anatase $\mathrm{TiO}_{2}(101)$ Surface. J. Phys. Chem. C 2014, 118, 21457-21462.

20. Meichtry, J. M.; Quici, N.; Mailhot, G.; Litter, M. I., Heterogeneous photocatalytic degradation of citric acid over $\mathrm{TiO}_{2}$ : II. Mechanism of citric acid degradation. Appl. Catal. B 2011, 102, 555-562. 
21. Mudunkotuwa, I. A.; Grassian, V. H., Citric Acid Adsorption on $\mathrm{TiO}_{2}$ Nanoparticles in Aqueous Suspensions at Acidic and Circumneutral $\mathrm{pH}$ : Surface Coverage, Surface Speciation, and Its Impact on Nanoparticle-Nanoparticle Interactions. J. Am. Chem. Soc. 2010, 132, 14986-14994.

22. Peper, J. L. Studies of Titanium Dioxide Nanoparticles: Thermodynamics and Reactivity. Yale University, 2019. p.55-59

23. Gutz, I. G. R., CurTiPlot - pH and Acid-Based Titration Curves: Analysis and Simulation freeware, version 4.2. $h$ ttp://www.iq.usp.br/qutz/Curtipot .html.

24. Bourikas, K.; Kordulis, C.; Lycourghiotis, A., Titanium Dioxide (Anatase and Rutile): Surface Chemistry, Liquid-Solid Interface Chemistry, and Scientific Synthesis of Supported Catalysts. Chem. Rev. 2014, 114, 9754-9823.

25. Fernández-Nieves, A.; de las Nieves, F. J.; Richter, C. In Point of zero charge estimation for a $\mathrm{TiO}_{2} /$ water interface, Trends in Colloid and Interface Science XII, Darmstadt, 1998; Koper, G. J. M.; Bedeaux, D.; Cavaco, C.; Sager, W. F. C., Eds. Steinkopff: Darmstadt, 1998; pp 21-24.

26. Morrison, S. R., The Solid/Liquid Interface. In Electrochemistry at Semiconductor and Oxidized Metal Electrodes, Plenum Press: New York, NY, 1980; pp 49-75.

27. Warren, J. J.; Tronic, T. A.; Mayer, J. M., Thermochemistry of Proton-Coupled Electron Transfer Reagents and its Implications. Chem. Rev. 2010, 110, 6961-7001.

28. Dung, D.; Ramsden, J.; Graetzel, M., Dynamics of Interfacial Electron-Transfer Processes in Colloidal Semiconductor Systems. Journal of the American Chemical Society 1982, 104, 2977-2985.

29. Nenadovic, M. T.; Rajh, T.; Micic, O. I.; Nozik, A. J., Electron Transfer Reactions and Flat-Band Potentials of Tungsten(VI) Oxide Colloids. J. Phys. Chem. 1984, 88, 5827-5830.

30. Carroll, G. M.; Schimpf, A. M.; Tsui, E. Y.; Gamelin, D. R., Redox Potentials of Colloidal n-Type ZnO Nanocrystals: Effects of Confinement, Electron Density, and Fermi-Level Pinning by Aldehyde Hydrogenation. J. Am. Chem. Soc. 2015, 137, 11163-11169.

31. Jakob, M.; Levanon, H.; Kamat, P. V., Charge Distribution between UV-Irradiated $\mathrm{TiO}_{2}$ and Gold Nanoparticles: Determination of Shift in the Fermi Level. Nano Lett. 2003, 3, 353-358.

32. Koelle, U.; Moser, J.; Graetzel, M., Dynamics of Interfacial Charge-Transfer Reactions in Semiconductor Dispersions. Reduction of Cobaltoceniumdicarboxylate in Colloidal Titania. Inorg. Chem. 1985, 24, 2253-2258.

33. Mohammad, M., Methyl viologen neutral MV. 1. Preparation and some properties. J. Org. Chem. 1987, 52, 2779-2782.

34. Watanabe, T.; Honda, K., Measurement of the extinction coefficient of the methyl viologen cation radical and the efficiency of its formation by semiconductor photocatalysis. J. Phys. Chem. 1982, 86, 2617-2619.

35. Ito, M.; Kuwana, T., Spectroelectrochemical study of indirect reduction of triphosphopyridine nucleotide: I. Methyl viologen, ferredoxin-TPN-reductase and TPN. J. Electroanal. Chem. Interfacial Electrochem. 1971, 32, 415-425.

36. Kosower, E. M.; Cotter, J. L., Stable Free Radicals. II. The Reduction of 1-Methyl-4-cyanopyridinium Ion to Methylviologen Cation Radical. J. Am. Chem. Soc. 1964, 86, 5524-5527.

37. Venturi, M.; Mulazzani, Q. G.; Hoffman, M. Z., Radiolytically-induced one-electron reduction of methyl viologen in aqueous solution: Stability of the radical cation in acidic and highly alkaline media. Radiat. Phys. Chem. 1984, 23, 229-236.

38. Liu, B.; Wang, Y. F.; Wang, J.; Gao, J.; Xu, R.; Kong, Y. M.; Zhang, L. Q.; Zhang, X. D., Syntheses and crystal structures of nine-coordinate $\mathrm{K}_{2}\left[\mathrm{Eu} \mathrm{u}^{\prime \prime \prime}(\mathrm{dtpa})\left(\mathrm{H}_{2} \mathrm{O}\right)\right] \cdot 5 \mathrm{H}_{2} \mathrm{O}$ and $\mathrm{Na}_{2}\left[\mathrm{~Tb}^{\prime \prime \prime}(\mathrm{Httha})\right] \cdot 6 \mathrm{H} 2 \mathrm{O}$ complexes. Journal of Structural Chemistry 2009, 50, 880-886.

39. Seibig, S.; Tóth, É.; Merbach, A. E., Unexpected Differences in the Dynamics and in the Nuclear and Electronic Relaxation Properties of the Isoelectronic [Eu'(DTPA) $\left.\left(\mathrm{H}_{2} \mathrm{O}\right)\right]^{3-}$ and $\left[\mathrm{Gd}^{\prime \prime \prime}(D T P A)\left(\mathrm{H}_{2} \mathrm{O}\right)\right]^{2-}$ Complexes (DTPA = Diethylenetriamine Pentaacetate). J. Am. Chem. Soc. 2000, 122, 5822-5830.

40. Vincent, K. A.; Tilley, G. J.; Quammie, N. C.; Streeter, I.; Burgess, B. K.; Cheesman, M. R.; Armstrong, F. A., Instantaneous, stoichiometric generation of powerfully reducing states of protein active sites using $\mathrm{Eu}(\mathrm{II})$ and polyaminocarboxylate ligands. 2003, 2590-2591. 